Bull. Mater. Sci., Vol. 6, No. 2, May 1984, pp. 283-316. (C) Printed in India.

\title{
Structure and superconductivity in ternary systems of compounds
}

\author{
G V SUBBA RAO* and GEETHA BALAKRISHNAN \\ Materials Science Research Centre, Indian Institute of Technology, Madras 600036, India \\ * Present Address: Alexander von Humboldt Fellow (1983-84), Anorg-Chem. Institute, \\ Westfälische Wilhelms University, 4400 Münster, West Germany
}

\begin{abstract}
A survey of the known high $T_{\mathrm{c}}$ ternary systems of compounds is presented. Special emphasis has been placed on the part played by the crystal structure and bonding in the exhibition of high $T_{\mathrm{c}}$ superconductivity. The superconducting and other physical properties of the ternary borides have been discussed in relatively more detail. Finally, the available guidelines from crystal and solid state chemistry points of view, have been reiterated for a search for new high $T_{r}$ materials.
\end{abstract}

Keywords. Ternary systems; superconducting compounds; metal excess systems.

\section{Introduction}

A ternary compound is one which contains three elements each occupying a distinct set or sets of crystallographic lattice sites and preferably one element should be a nonmetal. This crystallographic definition clearly distinguishes ternary compounds from binary or pseudo-binary phases in which only two sets of lattice sites are occupied or which contain only two species of elements. Metal excess ternary system of compounds (METS) are those in which only part of the valence electrons are involved in bonding (say, with the non metal) and the excess valence electrons of the metal(s) will partially fill the conduction band formed by the overlap of the requisite metal $s, p$ and $d$ orbitals (Hulliger 1981; Simon 1981; Corbett 1981). Thus, METs compounds invariably exhibit high electronic conductivity and metallic behaviour. Theoretical considerations reveal that superconductivity in a metallic material can occur whenever there is a large density of electronic states at the Fermi level in a partially filled conduction band (preferably a narrow band) and a favourable electron-phonon interaction. Hence METs, in principle, satisfy the requirements for the exhibition of superconductivity.

Superconductivity, the phenomenon of vanishing electrical resistance in a material below a critical temperature $\left(T_{c}>0 \mathrm{~K}\right)$, is not uncommon and many elements, alloys intermetallics, binary and ternary chemical compounds exhibit the behaviour. However, of the more than 1000 superconductors known, only a very limited number possess $T_{c}>10 \mathrm{~K}$ and the latter are called high temperature superconductors. It is now established that certain particular crystal structure of a binary or ternary (intermetallic or chemical) compound is very conducive to give rise to high $T_{c}$ superconductivity. The beta-tungsten ( $\mathrm{A}_{3} \mathrm{~B}$ or $\mathrm{A15}$ ) structure adopted by a large number of intermetallics is the well-known example. The phases $\mathrm{Nb}_{3} \mathrm{Al}$ and $\mathrm{Nb}_{3} \mathrm{Au}$ have a $T_{c}$ of 18 and $11 \mathrm{~K}$ respectively when crystallized in A15 structure but when prepared in a bcc form (with the same composition) they exhibit a $T_{c}$ of 4 and $1 \mathrm{~K}$. The binary metallic carbides 
Table 1. Structure and $T_{c}$ of high temperature ternary superconductors

\begin{tabular}{|c|c|c|c|c|}
\hline Compound & Structure type & Lattice parameter $(\mathbf{A})$ & $T_{c}(\mathbf{K})$ & Reference \\
\hline $\mathrm{LuRh}_{\mathbf{4}} \mathrm{B}_{\mathbf{4}}$ & $\mathrm{CeCo}_{4} \mathrm{~B}_{4}$ (tetra) & $a=5.3 ; c=7.4$ & $11 \cdot 7$ & $\begin{array}{l}\text { Vendenberg and } \\
\text { Matthias (1977) }\end{array}$ \\
\hline$Y\left(R h_{0.85} R u_{0.15}\right)_{4} B_{4}$ & $\mathrm{LuRh}_{4} \mathrm{~B}_{4}$ (tetra) & $a=7.5 ; c=14.9$ & 9.6 & Johnston (1977) \\
\hline LuRuB $_{2}$ & LuRuB $_{2}$ (ortho) & $a=5.8 ; b=5 \cdot 2 ; c=6.3$ & $10 \cdot 0$ & Ku and Shelton (1980) \\
\hline $\mathrm{Mo}_{3} \mathrm{Al}_{2} \mathrm{C}$ & Beta Mn (cubic) & $a=6.9$ & 100 & Johnston et al (1964) \\
\hline $\mathrm{Mo}_{2} \mathrm{BC}$ & $\mathrm{Mo}_{2} \mathrm{BC}$ (ortho) & $a=c=3 \cdot 1 ; b=17.4$ & 7.0 & Toth (1967) \\
\hline $\mathrm{Sc}_{5} \mathrm{Rh}_{4} \mathrm{Si}_{10}$ & $\mathrm{Sc}_{5} \mathrm{Co}_{4} \mathrm{Si}_{10}$ (tetra) & $a=12 \cdot 3 ; c=4 \cdot 0$ & 8.5 & Braun and Segre (1980) \\
\hline $\mathrm{Y}_{5} \mathrm{Os}_{4} \mathrm{Ge}_{10}$ & $\mathrm{Sc}_{5} \mathrm{Co}_{4} \mathrm{Si}_{10}$ (tetra) & $a=13.0 ; c=4.3$ & $8 \cdot 7$ & Braun and Segre (1980) \\
\hline $\mathrm{YbRh}_{1.4} \mathrm{Sn}_{4.6}$ & $\mathrm{Pr}_{3} \mathrm{Rh}_{4} \mathrm{Sn}_{13}$ & $a=9 \cdot 7$ & 8.6 & Remeika et al (1980) \\
\hline ZrRuP & $\mathrm{Fe}_{2} \mathrm{P}$ (hexa) & $a=6.4 ; c=3.8$ & $13 \cdot 0$ & $\begin{array}{l}\text { Barz et al }(1980) ; \\
\text { Müller et al }(1983)\end{array}$ \\
\hline NbPS & NbPS (ortho) & $\begin{array}{c}a=3 \cdot 4 ; b=11 \cdot 9 \\
c=4 \cdot 7\end{array}$ & $12 \cdot 5$ & $\begin{array}{l}\text { Donohue and } \\
\text { Bierstedt }(1969)\end{array}$ \\
\hline $\operatorname{LaRu}_{4} \mathrm{P}_{12}$ & $\mathrm{LaFe}_{4} \mathrm{P}_{12}$ (cubic) & $a=8 \cdot 1$ & $7 \cdot 2$ & Meisner (1981) \\
\hline $\mathrm{LiTi}_{2} \mathrm{O}_{4}$ & $\mathrm{MgAl}_{2} \mathrm{O}_{4}$ (spinel) & $a=8.4$ & 13.7 & Johnston (1976) \\
\hline $\mathrm{BaPb}_{0.8} \mathrm{Bi}_{0.2} \mathrm{O}_{3}$ & $\mathrm{CaTiO}_{3}$ (dist. perov) & $a \sim 5 \cdot 2$ & $13 \cdot 2$ & Sleight et al (1975) \\
\hline $\mathrm{Zr}_{0.6} \mathrm{Rh}_{0.3} \mathrm{O}_{0.1}$ & $\mathrm{Fe}_{3} \mathrm{~W}_{3} \mathrm{C}$ (cubic) & $a=12.4$ & $11 \cdot 8$ & Matthias et al (1963) \\
\hline $\mathrm{Pb}_{0.9} \mathrm{Mo}_{6} \mathrm{~S}_{7.5}$ & $\begin{array}{l}\mathrm{PbMo}_{6} \mathrm{~S}_{8} \\
\text { (rhombo-hexa) }\end{array}$ & $a=9 \cdot 2 ; c=11 \cdot 48$ & $15 \cdot 2$ & $\begin{array}{l}\text { Chevrel et al (1971); } \\
\text { Matthias et al (1972) }\end{array}$ \\
\hline $\mathrm{Cu}_{1.8} \mathrm{Mo}_{6} \mathrm{~S}_{8}$ & $\mathrm{PbMo}_{6} \mathrm{~S}_{8}$ (distorted) & $a=9.58 ; c=10.25$ & $10 \cdot 8$ & Matthias et al (1972) \\
\hline $\mathrm{Mo}_{6} \mathrm{~S}_{6} \mathrm{I}_{2}$ & $\mathrm{Mo}_{6} \mathrm{Se}_{8}$ & $a=9 \cdot 64 ; c=10.44$ & $14 \cdot 0$ & $\begin{array}{l}\text { Sergent et al (1977); } \\
\text { Perrin et al (1973). }\end{array}$ \\
\hline
\end{tabular}

crystallizing in $\mathrm{NaCl}$ or $\mathrm{Pu}_{2} \mathrm{C}_{3}$-structure types are the other examples. For the METs, the Chevrel phases $\left(\mathrm{AMo}_{6} \mathrm{~S}_{8}\right)$, rhodium borides $\left(\mathrm{LnRh}_{4} \mathrm{~B}_{4}\right.$-type), ordered $\mathrm{Fe}_{2} \mathrm{P}$-type phosphides constitute the relevant examples (table 1).

Since a large number of compounds are known or can be synthesized and also since chemical manipulation is more easily possible in them, the METs compounds do seem to offer a better scope for the realization of high $T_{c}$ and high critical magnetic field $\left(H_{c 2}\right)$ materials. As a result of intense research activity during the past decade many ternary METs have been isolated and studied and a wealth of information and interesting physics have come out not only with respect to the superconducting behaviour but also the coexistence of magnetic order and superconductivity, reentrant behaviour, intermediate valence and mixed (electronic and ionic) conduction.

In the following we give a concise but upto date account of the known high $T_{c}$ ( $\gtrsim 10 \mathrm{~K}$ ) compounds. Special emphasis will be placed on the part played by the crystal structure and bonding exhibited by them. We also give an account of some of the other known METs compounds that are yet to be tested for high $T_{c}$ behaviour.

\section{Ternary borides, $\mathbf{A} \mathbf{M}_{x} \mathbf{B}_{y}$}

\subsection{Compounds with $\mathrm{AM}_{4} \mathrm{~B}_{4}$ stoichiometry}

METs borides of the formula $\mathrm{AM}_{4} \mathrm{~B}_{\mathbf{4}}, \mathrm{A}=$ rare earth $(\mathrm{Ln}), \mathrm{Y}$, Th have been synthesized by Kuz'ma et al (1972) with $\mathrm{M}=\mathrm{Co}$ and by Vandenberg and Matthias (1977) with $\mathbf{M}=\mathbf{R h}$. These compounds possess a primitive tetragonal $\left(\mathrm{CeCo}_{4} \mathrm{~B}_{4}\right.$-type $)$ structure. Later studies have shown that $\mathrm{AM}_{4} \mathrm{~B}_{4}$-type compounds with $\mathrm{M}=\mathrm{Os}$, $\mathrm{Ir}$, $\mathrm{Ru}$ also exist 
with either primitive tetragonal $\left(\mathrm{NdCo}_{4} \mathrm{~B}_{4}\right.$-type), body centered tetragonal (bct, $\mathrm{LuRu}_{4} \mathrm{~B}_{4}$-type) or orthorhombic ( $\mathrm{LuRh}_{4} \mathrm{~B}_{4}$-type) structure (Johnston 1977; Ku et al 1979; Kuz'ma et al 1979; Rogl 1979; Rogl 1980; Yvon and Johnston 1982). Compound formation with the composition $\mathrm{AM}_{4} \mathrm{~B}_{4}$ has been reported with $\mathrm{M}=\mathrm{Fe}$ and $\mathrm{Re}$ but the structure has not yet been elucidated (Johnston and Braun 1982). The rhodium and iridium borides with the $\mathrm{CeCo}_{4} \mathrm{~B}_{4}$-type structure exhibit superconductivity while the isotypic cobalt borides have no transition above $1.5 \mathrm{~K}$. The rhodium borides, especially those containing non-magnetic rare earth $\mathrm{Lu}$ and $\mathrm{Y}$, exhibit high $T_{c}(11.7$ and $11.3 \mathrm{~K}$ respectively) (Matthias et al 1977; Johnston and Braun 1982). On the other hand, tetragonal compounds with the $\mathrm{NdCo}_{4} \mathrm{~B}_{4}$-type structure $\left(\mathrm{LnM}_{4} \mathrm{~B}_{4}\right.$ with $\mathrm{M}=\mathrm{Co}, \mathbf{R u}$, Os and $\mathrm{Ir}$ are only known but not with $\mathrm{M}=\mathrm{Rh}$ ) do not exhibit $T_{c}$ above $1 \mathrm{~K}$. The $b c t$ borides ( $\mathrm{LuRu}_{4} \mathrm{~B}_{4}$-type) and orthorhombic phases ( $\mathrm{LuRh}_{4} \mathrm{~B}_{4}$-type) do exhibit superconductivity. However, depending on the rare earth, $\mathrm{Y}$ or Sc occupying the lattice site, the $T_{c}$ varies only from 1.4-7.2 K. Extensive studies have been carried out on the ternary borides with the $\mathrm{CeCo}_{4} \mathrm{~B}_{4}$ - type structure by way of chemical substitution at the $\mathrm{Ln}$ and $\mathbf{M}$ sites and these help in establishing the systematics of superconductivity behaviour and structure-property correlations.

2.1a Structure: The four structure types exhibited by the $\mathrm{AM}_{4} \mathrm{~B}_{4}$ compounds (viz., primitive tetragonal $\mathrm{CeCO}_{4} \mathrm{~B}_{4}$ and $\mathrm{NdCo}_{4} \mathrm{~B}_{4}$-types; bct $\mathrm{LuRu}_{4} \mathrm{~B}_{4}$-type and orthorhombic $\mathrm{LuRh}_{4} \mathrm{~B}_{4}$-type) can be described by an arrangement of transition metal tetrahedra, isolated $A$ atoms (including the rare earths) and pairs of boron atoms. The $\mathrm{CeCO}_{4} \mathrm{~B}_{4}, \mathrm{LuRu}_{4} \mathrm{~B}_{4}$ and $\mathrm{LuRh}_{4} \mathrm{~B}_{4}$ structure-types are inter-related and all of them contain more or less isolated $\mathrm{M}_{4}$ tetrahedral clusters while in the $\mathrm{NdCo}_{4} \mathrm{~B}_{4}$-type, the $\mathbf{M}_{\mathbf{4}}$-clusters are fused together by sharing edges such that infinite chains are formed along the crystallographic $c$ direction.

In the $\mathrm{ARh}_{4} \mathrm{~B}_{4}$ compounds with the $\mathrm{CeCO}_{4} \mathrm{~B}_{4}$-structure, the $\mathrm{A}$ atoms and $\mathrm{Rh}_{4}$ clusters (slightly elongated with two short and four long $\mathrm{Rh}-\mathrm{Rh}$ distances along the tetragonal $a$ and $c$ axes respectively) occupy the positions of a slightly distorted $\mathrm{NaCl}$ lattice (figure 1a). Two orientations of $\mathrm{Rh}_{4}$ tetrahedra occur and the $\mathrm{Rh}$ network can be viewed as forming sheets in the $a-b$ plane (quasi two-dimensional extended clusters)

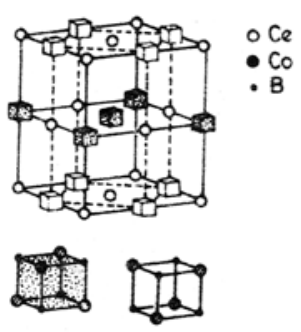

(a)

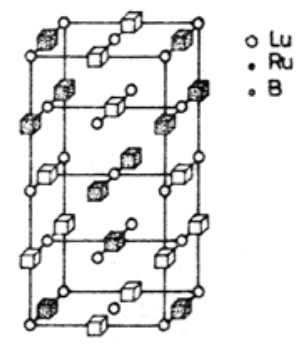

(b)

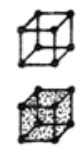

Figure 1. Idealized crystal structures of (a) primitive tetragonal $\mathrm{CeCO}_{4} \mathrm{~B}_{4}$-type and (b) body-centred tetragonal $\mathrm{LuRu}_{4} \mathrm{~B}_{4}$-type $\mathrm{AM}_{\mathbf{4}} \mathrm{B}_{4}$ compounds. The dashed lines in (a) outline the unit cell. Two orientations of $\mathbf{M}_{4}$ tetrahedra occur and for clarity, the $\mathbf{M}_{4} \mathrm{~B}_{4}$ cubes are not drawn to scale. The lattice parameters are: $\mathrm{CeCo}_{4} \mathrm{~B}_{4}$-type: $a \sim 5.3 \mathrm{~A} ; c \sim 7.4 \mathrm{~A}$; LuRu $\mathrm{B}_{4}$-type: $a \sim 7.5 \mathrm{~A} ; c \sim 14.9 \mathrm{~A}$. Actual values will depend on the $\mathrm{A}$ and $\mathrm{M}$ element. 
with an alternate arrangement (stacking) of tetrahedra of different orientations along the $c$-axis. The intra-cluster $\mathrm{Rh}$ - $\mathrm{Rh}$ distances (2.6-2.8 $\AA$ ) are approximately the same as in rhodium metal $(2.69 \AA)$ but intercluster distances are larger (3.1 $\AA$ ). The B-B distances are small $(1.80-1.83 \mathrm{~A})$ indicating pair formation whereas the $\mathrm{A}-\mathrm{A}$ distances are larger $(Z 5 \mathrm{~A})$ showing negligible interaction between them. However, significant bonding (charge transfer) exists between $R h$ and $B$ atoms.

The $b c t\left(\mathrm{LuRu}_{4} \mathrm{~B}_{4}\right.$-type) and orthorhombic $\left(\mathrm{LuRh}_{4} \mathrm{~B}_{4}\right.$-type) phases differ from the $\mathrm{CeCO}_{4} \mathrm{~B}_{4}$-type in the relative disposition of the isolated $\mathrm{M}_{4}$ clusters in the lattice; whereas the $\mathrm{M}_{4}$ tetrahedra of the same orientation are joined into sheets perpendicular to the $c$-axis in the $\mathrm{CeCo}_{4} \mathrm{~B}_{4}$-type, the $M_{4}$ tetrahedra of different orientations are distributed equally in each plane in an ordered fashion in the $\mathrm{LuRu}_{4} \mathrm{~B}_{4}$ - and $\mathrm{LuRh}_{4} \mathrm{~B}_{4}$ types (figure 1b) (Johnston 1977; Yvon and Grüttner 1980; Yvon and Johnston 1982). Thus, the bct and orthorhombic structures can be viewed as containing two interpenetrating three-dimensional networks or extended clusters of $\mathrm{M}_{4}$ tetrahedra. These extended clusters are qualitatively different from those in $\mathrm{CeCo}_{4} \mathbf{B}_{\mathbf{4}}$-type $\mathrm{AM}_{\mathbf{4}} \mathbf{B}_{\mathbf{4}}$ compounds, since in the latter phases they are quasi two-dimensional and do not interpenetrate. However, the unit cell dimensions of the three structures bear simple relationships to each other: $\sqrt{2} a \approx c\left(\mathrm{CeCo}_{4} \mathrm{~B}_{4}\right.$-type $) \approx a \approx(c / 2) \quad\left(\mathrm{LuRu}_{4} \mathrm{~B}_{4}-\right.$ type $) \approx a \approx(b / 3) \approx c\left(\mathrm{LuRh}_{4} \mathrm{~B}_{4}\right.$-type $)$.

The $\mathrm{NdCo}_{4} \mathrm{~B}_{4}$-type structure differs from the $\mathrm{CeCo}_{4} \mathrm{~B}_{4}$-type in two ways, viz. the $\mathrm{M}_{4}$ clusters are not isolated from each other but are fused together by sharing edges such that infinite chains are formed along the $c$-axis. Also, the A-A distances are small $(\sim 3.8-4 A \approx c$ lattice parameter) so that they can be considered to form infinite linear chains along the tetragonal axis (figure 2). On the other hand, the $A$ atoms in the $\mathrm{CeCo}_{4} \mathrm{~B}_{4}$ structure are well-separated from each other and form nearly $f c c$ array in the primitive tetragonal structure. The differences between the $\mathrm{CeCo}_{4} \mathrm{~B}_{4}$ and $\mathrm{NdCo}_{4} \mathrm{~B}_{4}$ structure types from a topological view point is also brought out by the fact that the $c / a$ ratio is $\sim 1.4$ in the former while it is much smaller $(\sim 0.53)$ in the latter. As will be discussed later, these structural differences play a crucial role in the $T_{c}$ behaviour of the compounds.

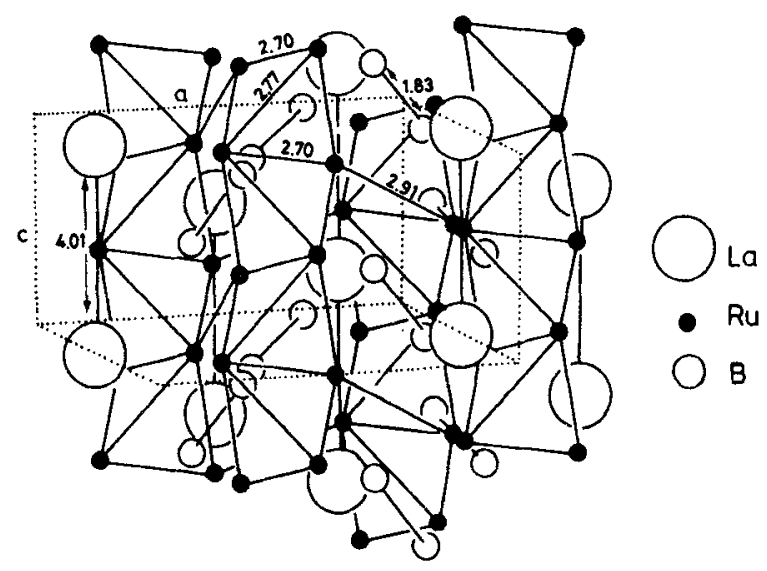

Figure 2. Structure of the tetragonal $\mathrm{LaRu}_{4} \mathrm{~B}_{4}$ viewed approximately perpendicular to the tetragonal axis. The numbers indicate the $\mathrm{Ru}-\mathrm{Ru}, \mathrm{La}-\mathrm{La}$ and $\mathrm{B}-\mathrm{B}$ bond lengths. The compound is isostructural to $\mathrm{NdCO}_{4} \mathrm{~B}_{4}$. The lattice parameters are $a=7.541 \mathrm{~A}, b=4.012 \mathrm{~A}$ (taken from Grüttner and Yvon 1979). 
2.1b Formation and stability: The formation and stability of the $\mathrm{AM}_{4} \mathrm{~B}_{4}$ compounds with different types of structures are dependent on the relative ionic sizes of the $A$ and $\mathbf{M}$ atoms, valence electron concentration and electronic factors. Thus, the proper phase with the $\mathrm{CeCO}_{4} \mathrm{~B}_{4}$-type structure is formed only for the following combinations of elements: $M=C o, A(L n)=C e, G d \rightarrow T m, L u ; M=R h, A=N d$, $\mathrm{Sm}, \mathrm{Gd} \rightarrow \mathrm{Tm}, \mathrm{Lu}, \mathrm{Y}$ and Th; M = Ir, Ln = Ho, Er and Tm. The bct $\mathrm{LuRu}_{4} \mathbf{B}_{4^{-}}$ structure easily forms for $\mathrm{M}=\mathrm{Ru}$ and $\mathrm{A}=\mathrm{Sc}, \mathrm{Y}, \mathrm{Th}, \mathrm{U}$ and $\mathrm{Ln}$ with the only exception when $\mathrm{Ln}=\mathrm{La}$. For $\mathrm{M}=\mathrm{Os}$, only $\mathrm{UOs}_{4} \mathrm{~B}_{4}$ has been isolated. We note that the proper phase with the $\mathrm{LuRu}_{4} \mathrm{~B}_{4}$-structure does not form for $\mathrm{M}=\mathrm{Co}$ and Rh. However, the structure with $M=R h$ can be stabilized at the nominal $A_{M} \mathbf{B}_{4}$ stoichiometry by substitution with a few atom percent of $\mathrm{Ru}$. Orthorhombic $\mathrm{LuRh}_{4} \mathrm{~B}_{4}$-type compounds are known only for $\mathrm{M}=\mathrm{Rh}$ and $\mathrm{Ln}=\mathrm{Ho} \rightarrow \mathrm{Lu}$. The $\mathrm{NdCO}_{4} \mathrm{~B}_{4}$-type structure is adopted for the following combinations: $\mathrm{M}=\mathrm{Co}$, $\mathrm{Ln}=\mathrm{La}, \mathrm{Nd}, \mathrm{Sm}, \mathrm{Eu} ; \mathrm{M}=\mathrm{Ru}, \mathrm{Ln}=\mathrm{La} ; \mathrm{M}=\mathrm{Os}, \mathrm{Ln}=\mathrm{La} \rightarrow \mathrm{Eu}, \mathrm{Th} ; \mathrm{M}=\mathrm{Ir}$, $\mathrm{Ln}=\mathrm{La} \rightarrow \mathrm{Dy}, \mathrm{Y}$ and $\mathrm{Th}$. Pseudoternary isostructural solid solutions easily form for isoelectronic $\mathrm{M}$ elements ( $\mathrm{M}=\mathrm{Ru}$ and $\mathrm{Os}$ or $\mathrm{Rh}$ and $\mathrm{Ir}$ ) but, interestingly enough, solid solutions are also found to form for the combinations $O s_{1-x} \operatorname{Ir}_{x}$ and $R h_{1-x} R_{u_{x}}$ with a given A element.

The $L v s r^{3+}$ plots, $L$ being the cube root of the volume associated with one formula unit of $\mathrm{AM}_{4} \mathrm{~B}_{4}$ and $r^{3+}$, the effective ionic radius of the trivalent rare earth atoms (Grüttner and Yvon 1979) is shown in figure 3. As can be seen the Rh- and Ru-based alloys which crystallize with the $\mathrm{CeCo}_{4} \mathrm{~B}_{4}$ - and $\mathrm{LuRu}_{4} \mathrm{~B}_{4}$-structure types respectively have practically the same atomic volume $(L)$. Since $\mathrm{Ru}$ and $\mathrm{Rh}$ atoms are very similar in size, this demonstrates the close structural relationship between these two series of compounds. Similar is the case with the Os and Ir alloys which crystallize with the

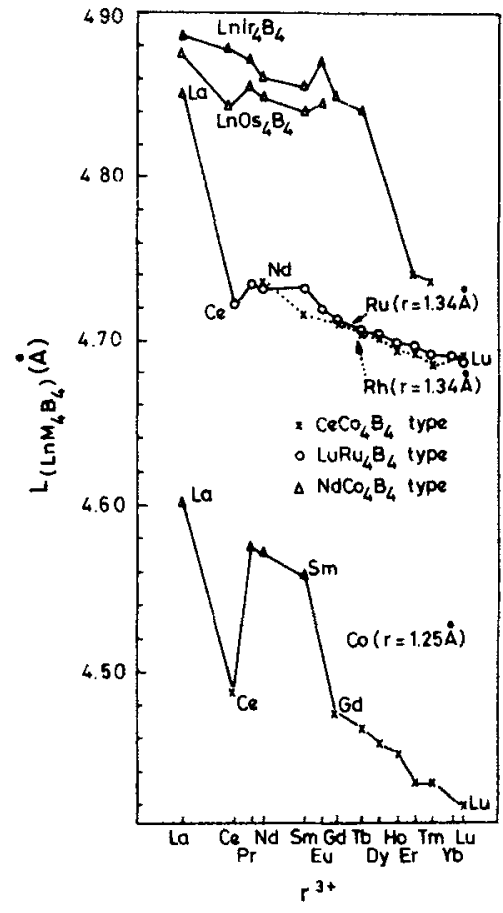

Figure 3. $L$ versus $r^{3+}$ diagram for the $\mathrm{LnM}_{4} \mathrm{~B}_{4}$ compounds containing $\mathrm{Co}, \mathrm{Rh}, \mathrm{Ru}, \mathrm{Os}$ and Ir. Full lines and dotted lines join compounds which contain the same transition element. 
$\mathrm{NdCO}_{4} \mathrm{~B}_{4}$-type structure. The formation of the $\mathrm{NdCo}_{4} \mathrm{~B}_{4}$-structure for the $\mathrm{Co}, \mathrm{Ru}, \mathrm{Os}$ and Ir-based alloys, on the other hand, is associated with a rather strong and discontinuous volume expansion and occurs for large ionic radii (lighter) rare earths (figure 3). The switchover from the $\mathrm{NdCo}_{4} \mathrm{~B}_{4}$-structure to the $\mathrm{CeCo}_{4} \mathrm{~B}_{4}$-structure occurs in the $\mathrm{Co}$ - and $\mathrm{Ir}$ based alloys for only the smaller ionic radii (heavier) rare earths $(\mathrm{Gd} \rightarrow \mathrm{Lu})$ indicating that geometric factors such as the radius ratio between the $\mathrm{Ln}$ and $\mathrm{M}$ atoms plays a major role in forming the proper phase. On the other hand, the formation and stability of the $\mathrm{CeCo}_{4} \mathrm{~B}_{4}$ - and $\mathrm{LuRu}_{4} \mathrm{~B}_{4}$-type compounds depends more on the electronic factors, valency of the $A$ atom and valence electron concentration (valence electron/atom ratio). Thus, the Rh-containing phases which normally crystallize with the $\mathrm{CeCo}_{4} \mathrm{~B}_{4}$-structure adopt the $\mathrm{LuRu}_{4} \mathrm{~B}_{4}$-structure if only $15 \%$ of $\mathrm{Rh}$ is substituted by $\mathrm{Ru}$ indicating that the arrangement of $\mathrm{M}$ atom sublattice in these two structure types is critically dependent on the valence electrons of the $M$ atoms ( $R h: 9$; $\mathrm{Ru}: 8$ electrons). Perhaps, similar behaviour might be exhibited by the $\mathrm{MIr}_{4} \mathrm{~B}_{4}$ phases $\left(\mathrm{CeCo}_{4} \mathrm{~B}_{4}-\right.$ structure $)$ doped with Os.

2.1c Superconducting properties: The $\mathrm{LnRh}_{4} \mathrm{~B}_{4}$ compounds with the $\mathrm{CeCo}_{4} \mathrm{~B}_{4}$-type structure have been studied extensively with respect to superconductivity and related physical properties. As mentioned earlier, the phases containing non-magnetic rare earths $\mathrm{Lu}$ and $\mathrm{Y}$ exhibit high $T_{c}$ values (table 2). For $\mathrm{Ln}=\mathrm{Nd}, \mathrm{Sm}, \mathrm{Er}$ and $\mathrm{Tm}$ which can support a magnetic moment due to the $4 f$-electrons, superconductivity is retained but with a lower $T_{c}(2 \cdot 7-9 \cdot 8 \mathrm{~K})$. However, for $\mathrm{Ln}=\mathrm{Gd}, \mathrm{Tb}, \mathrm{Dy}$ and $\mathrm{Ho}$, superconductivity is destroyed and the compounds order ferromagnetically with Curie temperatures ranging from 5-12 K (figure 4). The pure compound $E r \mathrm{Rh}_{4} B_{4}$ exhibits a reentrant (metallic) behaviour in the sense, on cooling to $0.9 \mathrm{~K}\left(T_{c}=8.7 \mathrm{~K}\right)$, the superconductivity is destroyed and the compound becomes a metal; almost simultaneously a ferromagnetic order develops and is retained up to the lowest attainable temperatures.

Solid solutions of the type $\left(\operatorname{Ln}_{1-x} \operatorname{Ln}_{x}^{\prime}\right) R_{h_{4}} B_{4}$ and $\operatorname{Ln}\left(\operatorname{Rh}_{1-x} \mathbf{M}_{x}\right)_{4} B_{4}(M=I r$ and $R u)$ have been examined in detail in the literature and provide a wealth of information on the interplay between superconductivity and magnetism in these materials. For the former type, an approximately linear variation of $T_{c}$ is noticed with $x$ (up to $x_{c}$, see figure 5) irrespective of the fact whether $\mathrm{Ln}$ and $\mathrm{Ln}^{\prime}$ carry local magnetic moments or not, provided the end members ( $x=0$ and 1$)$ form the proper phase with the $\mathrm{CeCo}_{4} \mathrm{~B}_{4}$-type structure. This behaviour indicates that the rare earth ion-conduction electron exchange interaction is weak in these materials.

Table 2. $T_{c}$ data on some representative $\mathrm{AM}_{4} \mathrm{~B}_{4}$ compounds $^{a}$

\begin{tabular}{|c|c|c|c|c|c|}
\hline \multicolumn{2}{|c|}{$\mathrm{CeCO}_{4} \mathrm{~B}_{4}$-type } & \multicolumn{2}{|l|}{ bct-LuRu $\mathrm{u}_{4} \mathrm{~B}_{4}-\mathrm{type}^{b}$} & \multicolumn{2}{|c|}{ Ortho $\mathrm{LuRh}_{4} \mathrm{~B}_{4}$-type } \\
\hline Phase & $T_{c}(\mathbf{K})$ & Phase & $T_{c}(\mathrm{~K})$ & Phase & $T_{c}(\mathbf{K})$ \\
\hline $\begin{array}{l}\mathrm{LuRh}_{4} \mathrm{~B}_{4} \\
\mathrm{YRh}_{4} \mathrm{~B}_{4} \\
\mathrm{ErRh}_{4} \mathrm{~B}_{4} \\
\mathrm{TmRh}_{4} \mathrm{~B}_{4}\end{array}$ & $\begin{array}{r}11 \cdot 7 \\
11 \cdot 3 \\
8 \cdot 7 \\
9 \cdot 8\end{array}$ & $\begin{array}{l}\mathrm{Lu}\left(\mathrm{Rh}_{0.85} \mathrm{Ru}_{0.15}\right)_{4} \mathrm{~B}_{4} \\
\mathrm{Y}\left(\mathrm{Rh}_{0.85} \mathrm{Ru}_{0.15}\right)_{4} \mathrm{~B}_{4} \\
\mathrm{Er}\left(\mathrm{Rh}_{0.85} \mathrm{Ru}_{0.15}\right)_{4} \mathrm{~B}_{4} \\
\mathrm{Tm}\left(\mathrm{Rh}_{0.85} \mathrm{Ru}_{0.15}\right)_{4} \mathrm{~B}_{4}\end{array}$ & $\begin{array}{l}9 \cdot 0 \\
9 \cdot 4 \\
7.9 \\
8 \cdot 3\end{array}$ & $\begin{array}{l}\operatorname{LuRh}_{4} \mathrm{~B}_{4} \\
\mathrm{ErRh}_{4} \mathrm{~B}_{4} \\
\mathrm{TmRh}_{4} \mathrm{~B}_{4}\end{array}$ & $\begin{array}{l}6 \cdot 2 \\
4 \cdot 3 \\
5 \cdot 4\end{array}$ \\
\hline
\end{tabular}

a Taken from Johnston and $\mathrm{Braun}$ (1982). Phases with the $\mathrm{NdCo}_{4} \mathrm{~B}_{4}$-type structure do not exhibit superconductivity above $1 \mathrm{~K}$.

${ }^{b} \mathrm{LuRu}_{4} \mathrm{~B}_{4}$ and $\mathrm{YRu}_{4} \mathrm{~B}_{4}$ have a $T_{c}$ of 2 and $1.4 \mathrm{~K}$ respectively. 


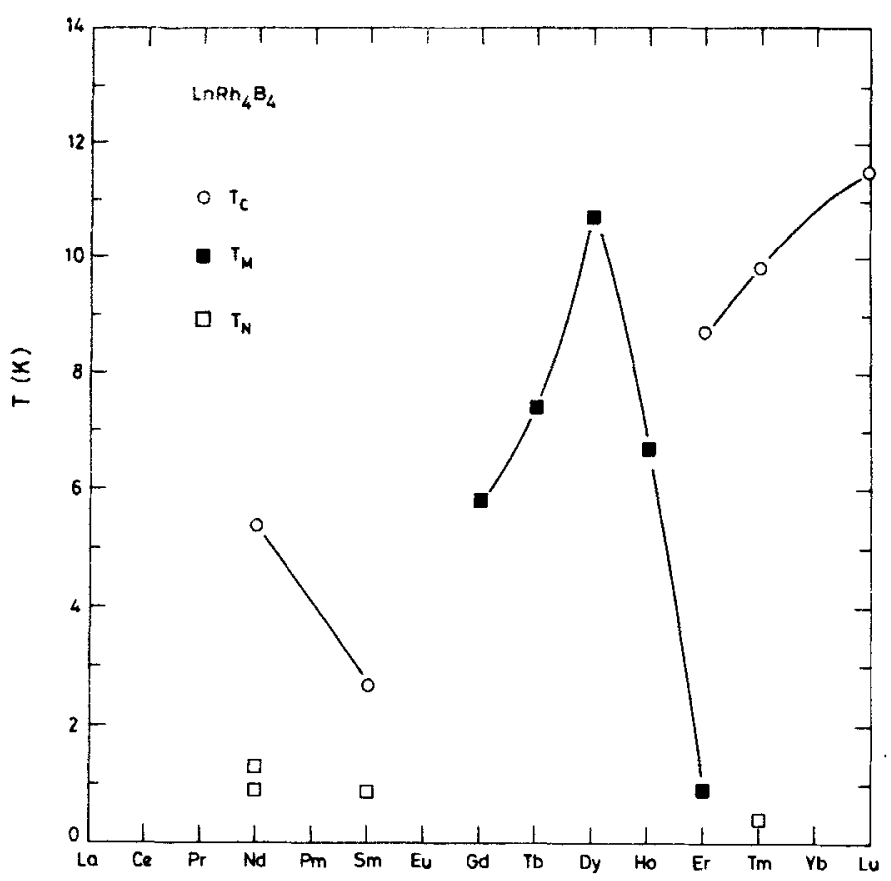

Figure 4. Superconducting $\left(T_{c}\right)$ ferromagnetic $\left(T_{M}\right)$ and antiferromagnetic $\left(T_{N}\right)$ transition temperatures of $\mathrm{LnRh}_{4} \mathrm{~B}_{4}$ compounds with the $\mathrm{CeCo}_{4} \mathrm{~B}_{4}$-structure. Phases with $\mathrm{Ln}=\mathrm{Nd}, \mathrm{Sm}$ and $T m$ exhibit antiferromagnetic order coexisting with superconductivity below $T_{N}$ while $\mathrm{ErRh}_{4} \mathrm{~B}_{4}$ orders ferromagnetically below $T_{M}$ with the destruction of superconductivity (reentrant behaviour). Phases with $\mathbf{L n}=\mathrm{Gd}, \mathrm{Tb}, \mathrm{Dy}$ and $\mathrm{Ho}$ exhibit ferromagnetic order below $T_{M}$ and do not exhibit superconductivity. Studies on the effect of pressure on $T_{c}$ and/or $T_{M}$ indicate positive coefficient of $\mathrm{d} T_{\mathrm{c}}(M) / \mathrm{d} P\left(\sim 1-2 \times 10^{-5} \mathrm{~K} /\right.$ bar $)$ except for $\mathrm{Ln}=\mathrm{Nd}$, Sm and Th where it is $\sim-0.5 \times 10^{-5} \mathrm{~K} /$ bar (Maple et al 1982; Shelton and Johnston 1978; Shelton et al 1980b).

Studies on the $\operatorname{Ln}\left(\operatorname{Rh}_{1-x} \operatorname{Ir}_{x}\right)_{4} B_{4}, \mathrm{Ln}=\mathrm{Lu}, \mathrm{Dy}$, Ho and Er solid solutions with the $\mathrm{CeCo}_{4} \mathrm{~B}_{4}$-type structure have shown that: (i) superconductivity is induced for $x \geqslant 0.2$ for $\mathrm{Ln}=\mathrm{Tb}, \mathrm{Dy}$ and Ho whereas the pure $x=0$ phases exhibit only ferromagnetism (figure 6), (ii) the superconducting transition temperature drops precipitously with increasing $x$ at $x=0.5-0.6$ and goes through a minimum for $x=0.8$ for $\mathrm{Ln}=\mathrm{Dy}$, Ho, $\mathrm{Er}$ and also for non-magnetic Lu (see figure 6). This observation shows that electronic band structure is getting affected and the nature of rare earth ion (both magnetic and non-magnetic) has little effect on the non-linear $T_{c}$ behaviour. Pseudoternary solid solutions of the non-isoelectronic type, $\operatorname{Ln}\left(\mathrm{Rh}_{1-x} \mathrm{Ru}_{x}\right)_{4} \mathrm{~B}_{4}$-type also exhibit interesting behaviour in the sense that superconductivity is induced for $x \geqslant 0.15$ for $\mathrm{Ln}=\mathrm{Pr}, \mathrm{Eu}$, $\mathrm{Dy}, \mathrm{Ho}, \mathrm{Er}$ and $\mathrm{Tm}$ whereas only long range magnetic ordering occurs for the isostructural $b c t \mathrm{LnRu}_{4} \mathrm{~B}_{4}$ with $\mathrm{Ln}=\mathrm{Nd}, \mathrm{Gd}, \mathrm{Tb}, \mathrm{Dy}, \mathrm{Ho}$ and $\mathrm{Er}$. Also, $T_{c}$ is enhanced for $x=0.15$ with $\mathrm{Ln}=\mathrm{Lu}$ and $\mathrm{Y}$ compared to the $x=0$ phases (see table 2). Nonlinear variation of $T_{c}$ with $x$ has been found in $\mathrm{Ln}\left(\mathrm{Rh}_{1-x} \mathrm{Ru}_{x}\right)_{4} \mathrm{~B}_{4}, \mathrm{Ln}=\mathrm{Y}, \mathrm{Er}$ and $\mathrm{Dy}$ at around $x=0.5-0.6$, a behaviour similar to that encountered in the $\operatorname{Ln}\left(\operatorname{Rh}_{1-x} \operatorname{Ir}_{x}\right)_{4} B_{4}$ series of compounds. This indicates that non-magnetic effects like crystallographic order in the $\mathrm{M}$ atom array are playing a role in determining the $T_{c}$ in these pseudoternaries. 


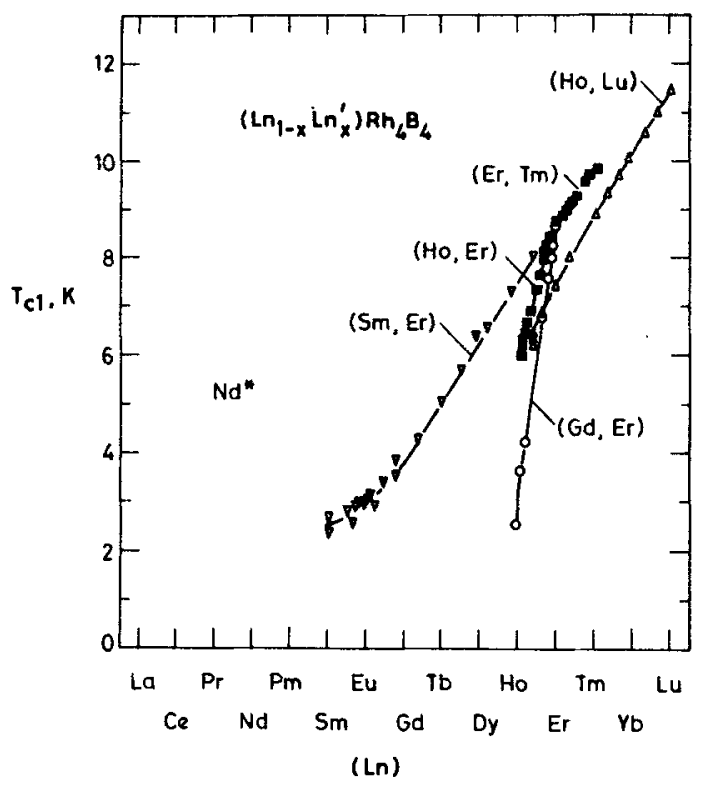

Figure 5. $T_{c} v s$ atomic number (or average atomic number) curves for ternary and pseudoternary $\left(\mathrm{Ln}_{1-x} L n_{x}^{\prime}\right) R_{4} B_{4}$ phases with the $\mathrm{CeCo}_{4} B_{4}$-structure (taken from Johnston and Braun 1982). The approximately linear variation of $T_{c}$ with composition (for $x<x_{c}$ ) irrespective of whether $\mathrm{Ln}$ or $\mathrm{Ln}^{\prime}$ carries a magnetic moment or not indicates that the conduction electron-localised spin interaction is small $\left(x_{c}\right.$ refers to the critical concentration at which $T_{c 1}, T_{c 2}$ and $T_{M}$ coincide).

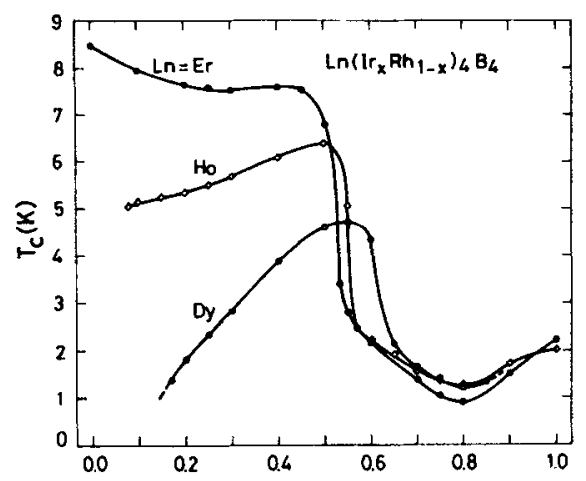

Figure 6. Variation of superconducting transition temperature $\left(T_{c}\right)$ with composition in the $\mathrm{CeCo}_{4} \mathrm{~B}_{4}$-type system $\operatorname{Ln}\left(\mathbf{R h}_{1-x} \mathbf{I r}_{\mathbf{x}}\right)_{4} \mathbf{B}_{4}$ (after $\mathbf{K u}$ and Acker 1980). As can be seen $T_{\mathrm{c}}$ drops precipitously at $x \sim 0.5-0.6$ and $T_{\mathrm{c}}$ goes through a minimum at around $x=0.8$.

The interesting and unusual properties of the $\mathrm{LnRh}_{4} \mathrm{~B}_{4}$ compounds with the $\mathrm{CeCo}_{4} \mathrm{~B}_{4}$-type structure can be explained on the basis of the crystal structure: (i) the isolated $\mathrm{Rh}_{\mathbf{4}}$ tetrahedral clusters with strong intra and significant intercluster interactions lead to the formation of partially filled conduction bands with a large density of states at the Fermi level $\left(E_{F}\right)$. Hence the $\mathrm{Rh} 4 d$-electrons are exclusively responsible for superconductivity and participate in the Cooper pair formation. This has been confirmed by magnetic susceptibility $(\chi)$ and other studies (Maple et al 1982) and band structure calculations (Freeman and Jarlborg 1982). As shown by the data in figure 5 , the $\mathrm{Ln}$ ions have only small but non trivial effect on $T_{c}$, (ii) the rare earth ions 
exist in $3+$ oxidation state in the lattice and effect a charge transfer (donation of 3 electrons) to the $\mathrm{Rh} 4 d$-conduction band. This has been confirmed by $\chi-T$ (Maple et al 1982) Mössbauer (Shenoy et al 1980) and neutron diffraction (Moncton et al 1977). Because the $\mathrm{Ln}$ - $\mathrm{Ln}$ separation is large, there is negligible interaction between them and any magnetic ordering due to $\mathrm{Ln}$-ions (which support a magnetic moment) occurs only at low temperatures ( $\leqslant 12 \mathrm{~K}$ ) and (iii) the boron atoms which exist as pairs play the role of anion and stabilize the structure.

The fact that a composition-induced redistribution of the electronic density of states at the $E_{F}$ may induce superconductivity and also bring drastic variation in $T_{c} v s x$ is shown by the solid solutions $\operatorname{Ln}\left(\mathrm{Rh}_{1-x} \mathrm{Ir}_{x}\right)_{4} \mathrm{~B}_{4}\left(\mathrm{CeCo}_{4} \mathrm{~B}_{4}\right.$-type; isoelectronic) and $\mathrm{Ln}\left(\mathrm{Rh}_{1-x} \mathrm{Ru}_{x}\right)_{4} \mathrm{~B}_{4}$; ( $\mathrm{LuRu}_{4} \mathrm{~B}_{4}-$ type; non-isoelectronic) where the integrity of the rare earth sublattice is undisturbed. The nonlinear variation of $T_{c}$ with composition and the precipitous decrease of it at $x \sim 0.5-0.6$ in both the above solid solution series have been correlated with the crystallographic $c / a$ parameter. For example, in $\operatorname{Ln}\left(\operatorname{Rh}_{1-x} \mathrm{Ir}_{x}\right)_{4} \mathbf{B}_{4} \cdot \mathrm{Ln}=\mathrm{Er}$ and Dy, Ku et al (1979) and Ku and Acker (1980) found that $c / a$ ratio which is constant for $x<0.50$, begins to decrease for $x=0.5-0.6$. Hence they suggested that for $x \leqslant 0 \cdot 5$, at least one pure $\mathrm{Rh}_{4}$ cluster per unit cell could exist whereas for $x>0.5$, a random distribution of $\mathrm{Rh}$ and $\mathrm{Ir}$ atoms in the $M_{4}$ cluster may exist to give rise to an abrupt decrease in $T_{c}$. Similarly, studies on $\operatorname{Lu}\left(\mathrm{Rh}_{1-x} \mathrm{Ru}_{x}\right)_{4} \mathrm{~B}_{4}$ system have shown that at $x=0.5-0.6$, a change in the $c / a$ ratio (from $<2$ to $>2$ ) and anomalous changes in the interatomic B-B and $\mathbf{M}-\mathbf{M}$ (intracluster) distances are observed (Yvon and Grüttner 1980; Johnston 1982).

The $\mathrm{AM}_{4} \mathrm{~B}_{4}$ phases with the bct $\mathrm{LuRu}_{4} \mathrm{~B}_{4}$ - or orthorhombic $\mathrm{LuRh}_{4} \mathrm{~B}_{4}$-type structure exhibit a lower $T_{c}$ compared to those possessing the $\mathrm{CeCo}_{4} \mathrm{~B}_{4}$-type structure. This is due to the differences in the mode of arrangement of the $\left(\mathrm{M}_{4} \mathbf{B}_{4}\right)$ tetrahedra of different orientations in the $a-b$ plane as well as the stacking of them along the $c$-axis. This can give rise to changes in the density of states at the Fermi level and/or electronphonon interaction leading to a lower $T_{c}$ in the $b c t$ and orthorhombic types. However, since isolated clusters exist in all the three structure types, the phases exhibit superconductivity. On the other hand, the $\mathrm{NdCo}_{4} \mathrm{~B}_{4}$-type structure is unfavourable to the occurrence of superconductivity since it does not contain isolated $\left(\mathbf{M}_{\mathbf{4}} \mathbf{B}_{4}\right)$ clusters and also, perhaps, because of the small $\mathrm{A}-\mathrm{A}$ separation.

2.1d Magnetic and non-magnetic contribution to the variation of $T_{c}$ : It is important to separate the magnetic from non-magnetic contributions to the variation of $T_{c}$ in analysing the data for a series of compounds containing rare earth elements. The magnetic contribution is usually analysed in terms of the Abrikosov-Gorkov (AG) theory according to which the exchange interaction between the conduction electrons with spin $s$ and local magnetic moment with spin $S(H=-2 I S \cdot s)$ results in a reduction of $T_{c}$ below the value $T_{c(0)}$ it would have had in the absence of exchange scattering, given by $\left(T_{c} / T_{c(0)}\right)=U\left(\alpha / \alpha_{c r}\right)$ where $U$ is a universal function of $\left(\alpha / \alpha_{c r}\right)$ (Maple 1976). The (Cooper) pair breaking parameter $\alpha$ is given by $\alpha=\left(n N\left(E_{F}\right) I^{2} / \hbar\right)(\mathrm{dGF})$ where the deGennes factor $(\mathrm{dGF})=(g-1)^{2} J(J+1), g$ and $J$ being, respectively, the Lande's $g$ factor and total angular momentum of the $\mathrm{Ln}^{3+}$ ion Hund's rule ground state. The $n$ represents the concentration of magnetic ions, $N\left(E_{F}\right)$ is the density of states at the Fermi level $\left(E_{F}\right)$ for each spin direction, $I$ is the exchange interaction parameter. $\alpha_{c r}$ is the value of $\alpha$ at which $T_{c}$ becomes zero. If $n, I, N\left(E_{F}\right)$ and $T_{c(0)}$ are the same for a given isostructural series of phases, then a plot of $T_{c}$ vs (dGF) should scale with the universal 


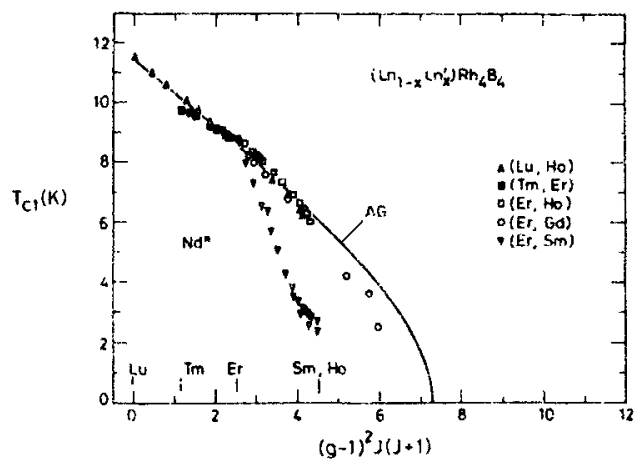

Figure 7. Superconducting transition temperature $T_{c}$ vs deGennes factor for pseudoternary solid solutions: $\left(\operatorname{Ln}_{x}^{\prime} \operatorname{Ln}_{1-x}\right) R h_{4} B_{4}$. The solid curve $A G$ is a fit to the data using the Abrikosov-Gorkov theory with the following parameters $T_{c(0)}=11.4 \mathrm{~K}$; $\left(\mathrm{d} T_{\mathrm{c}} / d(\mathrm{dGF})\right)=-1.09 \mathrm{~K} ; n J^{2} N\left(E_{F}\right)=2.04 \times 10^{-3} \mathrm{eV}$. The large parameters indicate an appreciably larger $N\left(E_{F}\right)$ and/or $J^{2}$ for heavy rare earth members of the $\mathrm{CeCo}_{4} \mathrm{~B}_{4}$ structure type. Significant negative deviation from AG curve exists for $\mathrm{Ln}=\operatorname{Pr}-\mathrm{Gd}$ (pure or alloys) (see text). (taken from Johnston and Braun 1982).

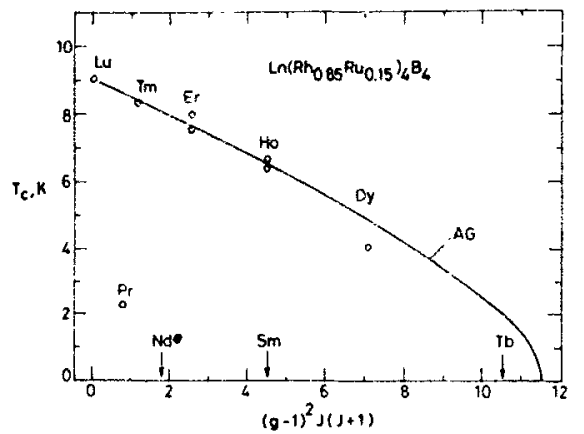

Figure 8. Superconducting transition temperature $T_{c}$ vs deGennes factor for the $\mathrm{LnRu}_{4} \mathrm{~B}_{4}$-type compounds: $\left(R_{0,85} R u_{0,15}\right)_{4} B_{4}$. The solid curve $A G$ is a fit to the data using the Abrikosov-Gorkov theory with the following parameters: $T_{s(0)}=9.05 \mathrm{~K}$; $\left(d T_{\mathrm{c}} / d(\mathrm{dGF})=-0.54 \mathrm{~K} ; \quad n I^{2} N\left(E_{F}\right)\right.$ $=0.94 \times 10^{-5} \mathrm{eV}$. The parameters are only half of those of figure 7. (Johnston and Braun 1982).

curve. In figures 7 and 8 are shown the available data on $\left(\operatorname{Ln}_{1-x} \operatorname{Ln}_{x}^{\prime}\right) R_{4} \mathbf{B}_{4}$ phases with the $\mathrm{CeCo}_{4} \mathrm{~B}_{4}$-type structure and $\operatorname{Ln}\left(\mathrm{Rh}_{0.85} \mathrm{Ru}_{0.15}\right)_{4} \mathrm{~B}_{4}$ compounds with the bct$\mathrm{LuRu}_{4} \mathrm{~B}_{4}$ structure. As can be seen, a good fit of the AG theory to the data is obtained for $\mathrm{Ln}=\mathrm{Ho} \rightarrow \mathrm{Lu}$ (for dGF $<5$ ) in both the series of compounds and suggests that $T_{c(0)}$ and $I^{2} N\left(E_{F}\right)$ are independent of $\operatorname{Ln}$ for these compounds. However, significant negative deviations occur for the lighter rare earths $(\mathrm{dGF} \geqslant 5)$ and the discrepancy (between theoretical and experimental curves) increases as the average size of the $\mathrm{Ln}$ increases past that of Ho. The discrepancy could be due to (i) breakdown of AG theory for dGF $\geqslant 5$; (ii) increase of $I^{2}$ and/or $N\left(E_{F}\right)$ with increasing ionic radius and/or the splitting of the Ln-ion energy levels by the crystalline electric field (CEF) which is generally larger for the lighter Ln's; (iii) non-magnetic effects, i.e. due to the inherent decrease in the value of $T_{c(0)}$. Experimental and theoretical studies on $\mathrm{SmRh}_{4} \mathrm{~B}_{4}$, $\left(\mathrm{La}_{x} \mathrm{Lu}_{1-x}\right) \mathrm{Rh}_{4} \mathrm{~B}_{4}\left(x=0.01-0.6, \mathrm{CeCo}_{4} \mathrm{~B}_{4}-\right.$ type $)$ and $\left(\mathrm{La}_{1-x} \mathrm{Lu}_{x}\right)\left(\mathrm{Rh}_{0.85} \mathrm{Ru}_{0.15}\right)_{4} \mathrm{~B}_{4}$ $\left(\mathrm{LuRu}_{4} \mathrm{~B}_{4}\right.$-type) indicate that the negative deviations of the data from $\mathrm{AG}$ theory in figures 7 and 8 arise largely due to a decrease in $T_{c(0)}$ (Hamaker et al 1979; Mackay et al 1980; Kumagai et al 1981; Johnston 1981). However, factors mentioned in (ii) above may also be responsible to a small extent. 
2.1e Coexistence of antiferromagnetism and superconductivity: Ternary rhodium borides, $\mathrm{LnRh}_{4} \mathrm{~B}_{4}$, are the ideal systems to study the interplay between magnetic order and superconductivity in materials for the following reasons: (i) The $\mathrm{Ln}$ ions are distributed uniformly throughout the crystal lattice (i.e., form part of the network structure) but situated far of from the conduction electron system ( $R h-4 d$ conduction band) so that there is negligible exchange interaction between the localized electron spins and the electrons responsible for superconductivity. (ii) Rare earth concentration is large $(\sim 11$ atom $\%)$ and in cases where the ions can support a large magnetic moment, magnetic ordering can be expected at low temperatures by interatomic exchange or superexchange interaction. If the rare earth spins are to order antiferromagnetically, there is no macroscopic internally-generated magnetic field to disturb the superconducting state. Hence the coexistence of antiferromagnetic order and superconductivity is expected and indeed observed in $\operatorname{LnRh}_{4} B_{4}$ compounds and other related materials. Theoretical treatments have also been successfully developed (Jaric 1979, 1980; Ramakrishnan and Varma 1981; Sakai et al 1981; Mahanti et al 1981; Suzumura and Nagi 1982).

Detailed studies by way of $\chi-T, \rho-T, C_{p}, H_{c 2}$ and neutron diffraction have shown that $\mathrm{LnRh}_{4} \mathrm{~B}_{\mathbf{4}}, \mathrm{Ln}=\mathrm{Nd}, \mathrm{Sm}$ and $\mathrm{Tm}$ exhibit the coexistence behaviour in zero applied magnetic fields with the Néel temperature, $T_{N}<T_{\mathrm{c}}$ (table 3 and figure 9). Pseudoternary alloys also show this behaviour but a few systems are interesting in that they have $T_{N}>T_{c}$. Theoretical models explaining the coexistence behaviour should take cognizance of this fact. The antiferromagnetism (afm) is exclusively due to the $\mathrm{Ln}$ ions but the exact type of ordering has not been established in all the boride phases.

Table 3. Antiferromagnetic superconductors ${ }^{a}$

\begin{tabular}{|c|c|c|}
\hline Compound & $\begin{array}{l}\text { Superconductors } \\
T_{c}(\mathrm{~K})\end{array}$ & $\begin{array}{c}\text { Antiferromagnetic } \\
\text { Nèel temperature } \\
T_{N}(\mathrm{~K})\end{array}$ \\
\hline \multicolumn{3}{|l|}{ Rhodium borides } \\
\hline $\mathrm{NdRh}_{4} \mathrm{~B}_{4}$ & $5 \cdot 36$ & $1 \cdot 3,0.9^{b}$ \\
\hline $\mathrm{SmRh}_{4} \mathrm{~B}_{4}$ & $2 \cdot 72$ & $0 \cdot 87$ \\
\hline $\mathrm{TmRh}_{4} \mathrm{~B}_{4}$ & 9.86 & 0.4 \\
\hline $\mathrm{Ho}\left(\mathrm{Rh}_{0.3} \mathrm{It}_{0.7}\right)_{4} \mathrm{~B}_{4}$ & $1 \cdot 34$ & $2 \cdot 7$ \\
\hline $\operatorname{Dy}\left(R h_{0.85} R u_{0.15}\right)_{4} B_{4}$ & $4 \cdot 0$ & $1 \cdot 5^{c}$ \\
\hline $\operatorname{Dy}\left(R h_{0.3} I r_{0.7}\right)_{4} B_{4}$ & $1 \cdot 7$ & $4 \cdot 7^{d}$ \\
\hline \multicolumn{3}{|l|}{ Chetrel phases } \\
\hline $\mathrm{NdMo}_{6} \mathrm{~S}_{8}$ & $3.3(3.6)^{e}$ & $0.85(?)$ \\
\hline $\mathrm{GdMo}_{6} \mathrm{~S}_{8}$ & $1 \cdot 1(1.4)$ & $0.85(0.95)$ \\
\hline $\mathrm{TbMo}_{6} \mathrm{~S}_{8}$ & $1.45(1.80)$ & $0.90(1.05)$ \\
\hline $\mathrm{DyMo}_{6} \mathrm{~S}_{8}$ & $2 \cdot 05(2 \cdot 15)$ & $0.40(0.45)$ \\
\hline $\mathrm{ErMo}_{6} \mathrm{~S}_{8}$ & $1 \cdot 9(2 \cdot 2)$ & $0.15(0.22)$ \\
\hline $\mathrm{YbM}_{6} \mathrm{~S}_{8}$ & $9 \cdot 2(9 \cdot 5)$ & $2.6(2 \cdot 75)(?)$ \\
\hline $\mathrm{GdMo}_{6} \mathrm{Se}_{8}$ & $5 \cdot 6$ & 0.75 \\
\hline $\mathrm{TbMo}_{6} \mathrm{Se}_{8}$ & $5 \cdot 7$ & $1.03(?)$ \\
\hline $\mathrm{ErMo}_{6} \mathrm{Se}_{8}$ & 6.0 & $1 \cdot 07$ \\
\hline
\end{tabular}

a Taken from Subba Rao and Shenoy (1981); ${ }^{b}$ Two transitions are indicated; ${ }^{c}$ Hamaker and Maple (1981); ${ }^{d} \mathrm{Ku}$ and Acker (1980); ${ }^{e}$ Values in paranthesis are the onset temperatures. (?) indicates that the detailed nature of the antiferromagnetic order has not yet been established. 


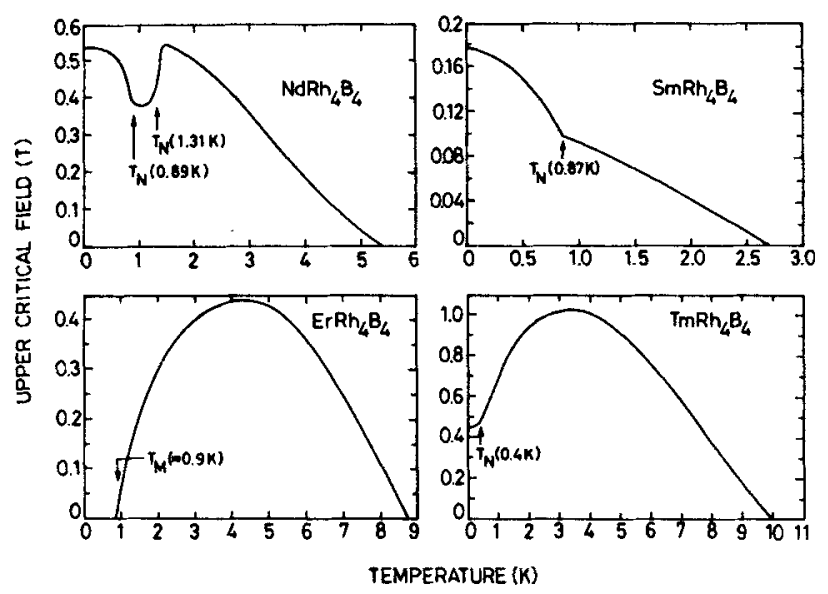

Figure 9. Upper critical magnetic field vs temperature for $\mathrm{NdRh}_{4} \mathrm{~B}_{4}, \mathrm{SmRh}_{4} \mathrm{~B}_{4}, \mathrm{ErRh}_{4} \mathrm{~B}_{4}$ and $\mathrm{TmRh} \mathrm{h}_{4} \mathrm{~B}_{4}$. As can be seen in the compounds with $\mathrm{Ln}=\mathrm{Nd}, \mathrm{Sm}, \mathrm{Tm}$, superconductivity coexists with antiferromagnetism. $\mathrm{ErRh}_{4} \mathrm{~B}_{4}$ exhibits a reentrant behaviour (taken from Maple et al 1982).

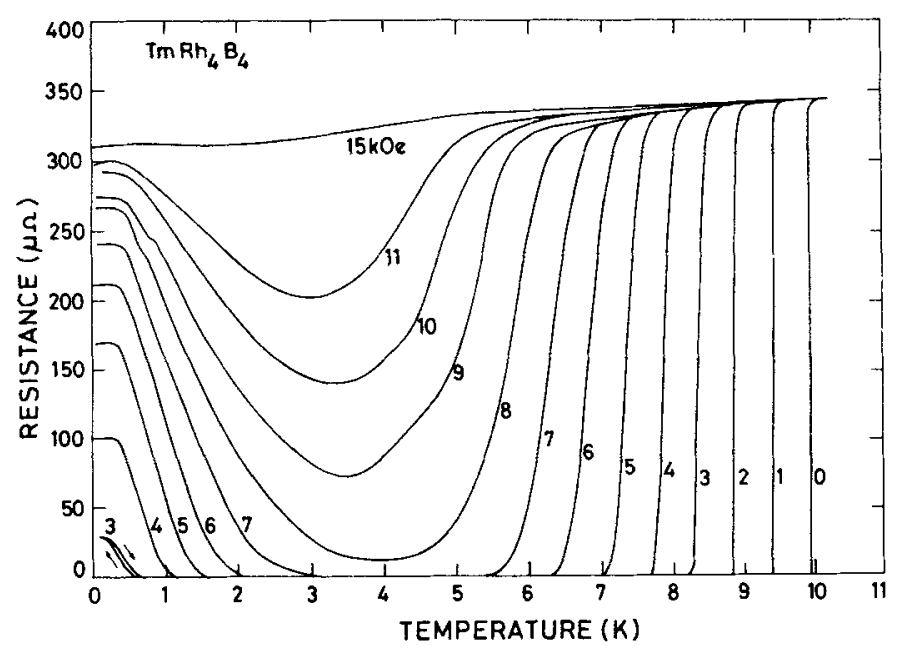

Figure 10. Resistivity vs temperature curves at various applied magnetic fields (kOe) for $\mathrm{TmRh}_{4} \mathrm{~B}_{4}$. Notice that antiferromagnetic order below $T_{\mathrm{c}}$ gets modified with the applied field (taken from Subba Rao and Shenoy 1981).

Ku et al (1980) pointed out that the complex magnetic ordering (as compared to simple afm or fm order) might be a common feature of several $\mathrm{LnRh}_{4} \mathrm{~B}_{4}$ compounds where $\mathrm{Ln}$ is heavier than $\mathrm{Gd}$. Antiferromagnetic superconducting ternary borides become normal (reentrant behaviour) at $T_{N}$ and develop some sort of ferromagnetic order by the application of magnetic field $\left(H \leqslant H_{c 2}\right)$ (figure 10).

2.1f Reentrant and ferromagnetic superconductors: If the rare earth spins in a $\mathrm{LnRh}_{4} \mathrm{~B}_{4}$ systems are to order ferromagnetically the macroscopic dipolar field so created will strongly become competitive with the superconductivity and destroy the 
latter once the critical magnetic field value for the destruction of superconducting state is reached. Before the full realization of ferromagnetic state (reentrant behaviour), however, the ferromagnetic correlations may lead to an oscillatory magnetic state and the latter can coexist with superconductivity. This has been amply verified in $E r R_{4} B_{4}$ (see below). Theoretical investigations by many workers (Suhl 1978; Ferrel et al 1979; Bulaevski et al 1979; Matsumoto et al 1979; Machida and Matsubara 1979; Greenside et al 1981) predict the possibility of several types of the oscillatory magnetic state (spiral, vortex or linearly polarized) but the experimental evidence on $\mathrm{ErRh}_{4} \mathrm{~B}_{4}$ and $\mathrm{HoMo}_{6} \mathrm{~S}_{8}$ are in favour of transverse linearly polarized state which is coexisting with the superconducting state.

As mentioned earlier, the compound $\mathrm{ErRh}_{4} \mathrm{~B}_{4}$ exhibits reentrant superconductivity in zero applied magnetic field with the upper and lower superconducting critical temperatures $T_{c 1}=8.7 \mathrm{~K}$ and $T_{c 2} \approx 0.9 \mathrm{~K}$ respectively, due to the onset of long range ferromagnetic order (alignment of $\mathrm{Er}^{3+}$ spins in the basal $(a-b)$ plane) at a temperature $T_{M} \sim T_{c 2}$ (see figure 9). Thermal hysteresis at $T_{c 2}$ is observed in the measured $\rho, \chi$ and $C_{p}$ (Lander et al 1979; Moncton et al 1980) and thermal conductivity data (Odoni and Ott 1979) indicating that the transition is first order. Interesting precursor effects by way of the existence of a small angle peak in neutron diffraction have been observed by Moncton et al (1980) in $\operatorname{ErRh}_{4} \mathbf{B}_{4}$ in the superconducting state above the magnetic transition temperature. Recent careful neutron diffraction and resistivity studies at low temperatures on single crystals of $\mathrm{ErRh}_{4} \mathrm{~B}_{4}$ by Sinha et al (1982) have shown that the transition from superconductivity to ferromagnetism proceeds through an intermediate mixed state which displays both superconductivity and long-range magnetic order. This mixed state (or pseudo phase), a mosaic of microscopic superconducting and ferromagnetic regions of size $2000 \mathrm{~A}$, sets in when the sample is cooled to below $1.2 \mathrm{~K}$ and exhibits a ferromagnetic moment and modulated moment (transverse linearly polarized, with a period of $91.8 \pm 2.7 \AA$ ). On further cooling to $0.71 \mathrm{~K}$, the crystal enters into a purely ferromagnetic phase, with the modulated moment and superconductivity disappearing simultaneously (figure 11). The latter appears suddenly on warming to $0.775 \mathrm{~K}$. This first order transition is mirrored in the opposite sense by the behaviour of ferromagnetic intensity. An interesting effect of magnetic field on the intermediate mixed state has also been observed by Sinha et al (1982). Application of 200 Oe field to the sample at $0.74 \mathrm{~K}$ in the superconducting state (reached on cooling) did not produce a change in the satellite periodicity (wavelength of the modulated structure) but its intensity decreased by $45 \%$ while the ferromagnetic intensity increased by $8.8 \%$. On switching off the external field, the intensity pattern did not restore itself to the previous zero-field value until the sample had been warmed beyond $T_{m}(1 \cdot 2 \mathrm{~K})$ and recooled.

Reentrant superconductivity is also found in atleast three pseudoternary $\operatorname{Ln} M_{4} B_{4}$ alloys (table 4) indicating that it is a common phenomena and is not restricted to some special systems. Ku and Shelton (1981) pointed out that a ferromagnetic order may not be necessary to destroy superconductivity in a ternary system. Thus, any type of magnetic order with an internal exchange magnetic field that is large compared to upper critical field $H_{\mathrm{c} 2}$ when averaged over the superconducting coherence length, will be able to destroy the superconductivity and thus show the reentrant property. When searching for a pseudoternary low temperature phase diagram that may exhibit reentrant superconductivity one must consider, in addition to the ordered states of the pure ternary end members, the rate of depression with composition of both $T_{c}$ and $T_{m}$ which 


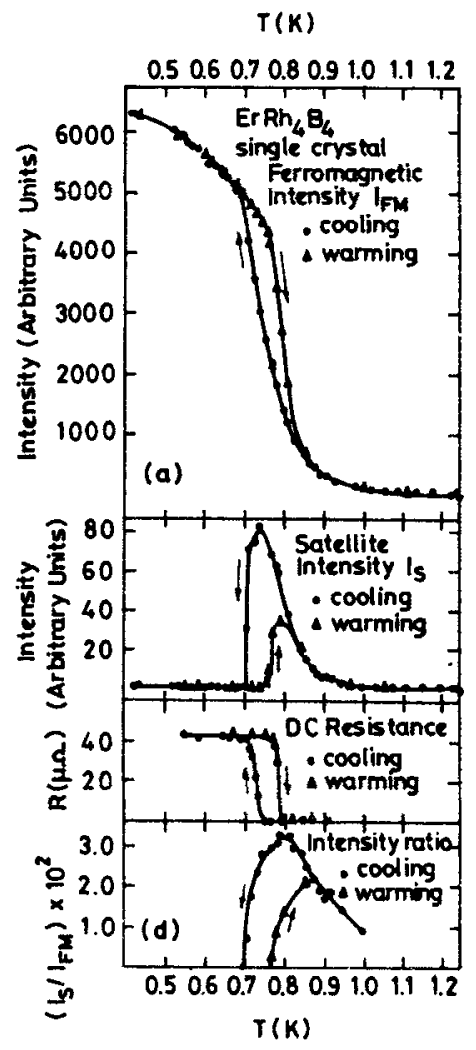

Figure 11. Neutron diffraction and resistivity study of single crystal $\mathrm{ErRh}_{4} \mathrm{~B}_{4}$ in the low temperature region. Temperature dependence of (a) ferromagnetic intensity from the (101) Bragg peak (b) satellite intensity due to the modulated magnetic structure (c) bulk dc resistivity and (d) ratio of the satellite to the ferromagnetic intensity for the (101) reciprocal lattice point. Hysteresis is clearly shown in all cases (after Sinha et al 1982).

should be sufficiently small to allow these two types of transitions to intersect. Other pseudoternary systems similar to those shown in figure 12 and $\operatorname{Ln}\left(\operatorname{Rh}_{1-x} \mathbf{M}_{x}\right)_{4} \mathbf{B}_{4}$ $(\mathbf{M}=\mathbf{R u}, \mathrm{Ir}, \mathrm{Os}$ ) can thus be profitably be examined.

Coexistence of ferromagnetism and superconductivity has recently been realized in the alloy system $\left(\mathrm{Ho}_{x} \mathrm{Er}_{1-x}\right) \mathrm{Rh}_{4} \mathbf{B}_{4}(0-84 \leqslant x \leqslant 09)$ in the temperature range 4.95-5.95 $\mathrm{K}$ (for $x=0.84$ ) and has been conclusively established by $\chi, \rho$ and neutron diffraction techniques (table 4; Lynn 1983; Lynn et al 1983a,b). No evidence for an oscillatory component due to the magnetization was found and in this respect the alloy system differs from the behaviour of pure $\mathrm{ErRh}_{4} \mathrm{~B}_{4}$.

\subsection{Compounds with $A M B_{2}$ stoichiometry}

$\mathrm{Ku}$ and Shelton (1980) and Sheli on et al (1980b) discovered that $\mathrm{LnMB}_{2}$ ( $\mathrm{Ln}=$ rare earth, $\mathrm{Y}$ and $\mathrm{Sc} ; \mathrm{M}=\mathrm{Ru}$ and $\mathrm{Os}$ ) crystallize with the orthorhombic structure and $\mathrm{LuRuB}_{2}$ and $\mathrm{YRuB}_{2}$ exhibit high temperature superconductivity with $T_{c}$ of 10 and $7.8 \mathrm{~K}$ respectively. However, the corresponding Os-containing isoelectronic compounds have $T_{c}$ lowered by a factor of 4 . When $\mathrm{Ln}$ is a magnetic ion, the phases exhibit magnetic ordering, presumably of a ferromagnetic-type. Ku and Shelton (1981) examined the pseudoternary system $\left(\mathrm{Lu}_{1-x} \mathrm{Tm}_{x}\right) \mathrm{RuB}_{2}$ and found reentrant superconducting behaviour for $0.52 \leqslant x \leqslant 0.68$ (Table 4).

The structure of orthorhombic $\mathrm{LuRuB}_{2}$ is shown in figure 13. It is a cluster compound qualitatively of a different kind from that of the $\mathrm{AM}_{4} \mathrm{~B}_{4}$-type compounds. 
Table 4. Reentrant and ferromagnetic superconductors

\begin{tabular}{|c|c|c|c|}
\hline Compound & $\begin{array}{l}\text { Superconductors } \\
T_{c}\left(\equiv T_{c 1}\right)(\mathrm{K})\end{array}$ & $\begin{array}{l}\text { Reentrant temperature } \\
T_{r 2}\left(\leqslant T_{m} \text {, mag. order }\right. \\
\text { temperature) }(\mathbf{K})\end{array}$ & Reference \\
\hline $\mathrm{ErRh}_{4} \mathrm{~B}_{4}$ & 8.7 & $\begin{array}{l}0.71 \text { (cooling) } \\
0.775 \text { (warming) } \\
\left(T_{m}<1.2 \mathrm{~K}\right)\end{array}$ & Sinha et al (1982) \\
\hline $\mathrm{Tm}_{2} \mathrm{Fe}_{3} \mathrm{Si}_{5}$ & 1.7 & $1 \cdot 13$ & Segre and Braun (1981) \\
\hline $\mathrm{TmOs}_{x} \mathrm{Sn}_{y}$ & $1 \cdot 1$ & 0.6 & Fisk et al (1982) \\
\hline $\mathrm{ErRh}_{1.1} \mathrm{Sn}_{3.6}$ & 1.36 & $0-46$ & Remeika et al (1980) \\
\hline $\operatorname{ErOs}_{1,4} \mathrm{Sn}_{2.7}$ & $1 \cdot 3$ & 0.5 & Fisk et al (1982) \\
\hline $\mathrm{HoMo}_{6} \mathrm{~S}_{8}$ & $1 \cdot 82$ & $\begin{array}{l}0612 \text { (cooling) } \\
0-668 \text { (warming) }\end{array}$ & Lynn et al (1981, 1983a) \\
\hline $\begin{array}{l}\mathrm{Ho}\left(\mathrm{Rh}_{1-x} \mathrm{I} \mathrm{I}_{x}\right)_{4} \mathrm{~B}_{4} \\
(x=0.15) \\
(0-08 \leqslant x \leqslant 0-22)\end{array}$ & 52 & 20 & Kuet al (1980) \\
\hline $\begin{array}{l}\left(\mathrm{Y}_{1-x} \mathrm{Gd}_{x}\right) \mathrm{Rh}_{4} \mathrm{~B}_{4} \\
(x=0-32)\end{array}$ & 2.82 & 1.72 & Adrian et al (1981) \\
\hline $\begin{array}{l}\operatorname{Tm}_{1-x} \mathrm{Lu}_{x} \mathrm{RuB}_{2} \\
(x=0.6) \\
(0.52 \leqslant x \leqslant 0.68)\end{array}$ & $4 \cdot 3$ & $1 \cdot 2$ & $\mathrm{Ku}$ and Shelton (1981) \\
\hline \multicolumn{4}{|l|}{$\begin{array}{l}\text { Ferromaynetic }{ }^{b} \\
\text { supercondiuctors }\end{array}$} \\
\hline$\left(\mathrm{Ho}_{0.84} \mathrm{Er}_{0.16}\right) \mathrm{Rh}_{4} \mathrm{~B}_{4}$ & $5-95$ & $\begin{array}{l}4.95 \text { (resist.) } \\
5.30 \text { (neutron) }\end{array}$ & $\begin{array}{l}\text { Lynn 1983: } \\
\text { Lynn et al (1983b) }\end{array}$ \\
\hline$\left(\mathrm{Ho}_{0.5} \mathrm{Eu}_{0.5}\right) \mathrm{Mo}_{6} \mathrm{~S}_{8}$ & 2.0 & $0 \cdot 6$ & Ishikawa et al (1981; 1982) \\
\hline
\end{tabular}

a Below $T_{m}$ an intermediate mixed state sets in where ferromagnetic domains and superconducting domains coexist (of size $\sim 2000 \mathrm{~A}$ ), with the superconducting domains further divided into subdomains which contain modulated magnetic moment.

' Coexistence of ferromagnetism and superconductivity occurs in the interval $T_{c 2}<T<T_{c 1}$ for the specific compositions.

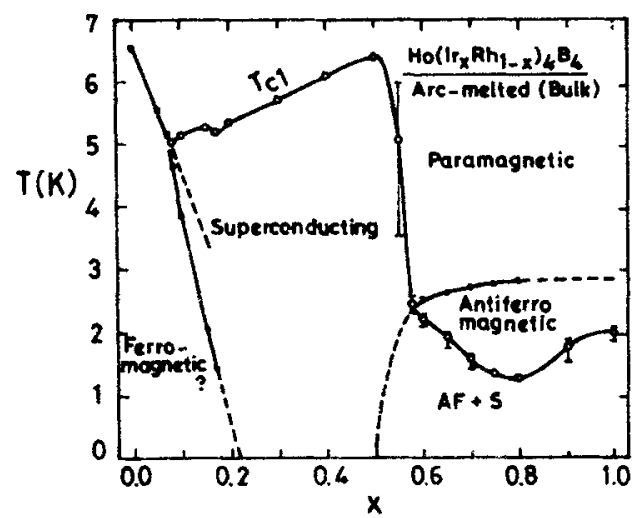

Figure 12. Low temperature phase diagram for the system $H_{0}\left(\operatorname{Ir}_{x} \mathrm{Rh}_{1-x}\right)_{4} \mathbf{B}_{4}$ determined from ac and static susceptibility measurements on arc melted samples. This system is interesting in that both reentrant behaviour and the coexistence of antiferromagnetism and superconductivity $\left(T_{N}>T_{c}\right)$ are encountered with varying $x$ (taken from $\mathrm{Ku}$ et al 1980). 


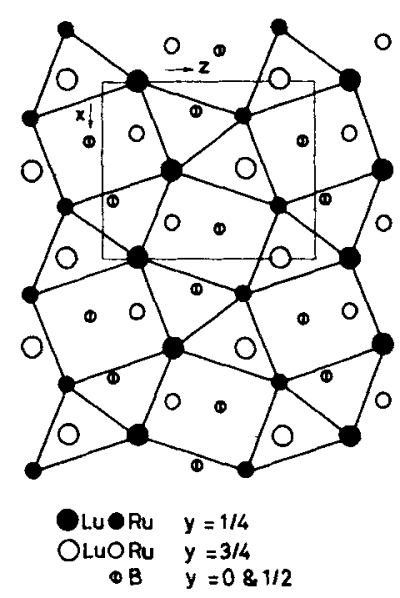

Figure 13. Projection of the orthorhombic $\mathrm{LuRuB}_{2}$ type structure along the (010) direction. Plane net of $\mathrm{Lu}$ and $R u$ atoms are connected by thick lines for $y=1 / 4$ plane.

The $\mathrm{Lu}$ and $\mathrm{Ru}$ atoms form planar nets perpendicular to the $b$-axis. The Lu-Lu distance within the plane is very short (3.1 A compared to the normal CN12 metallic distance of 3.47 A) and interlayer distance is only slightly larger (3.34 $\AA$ ). The intralayer and interlayer $\mathrm{Ru}$ - $\mathrm{Ru}$ distances are 3.03 and 4.07 A respectively (compare $\mathrm{Ru}$ - $\mathrm{Ru}$ distance of $2.71 \mathrm{~A}$ in $\mathrm{Ru}$ metal). The Lu atoms form zig-zag chain clusters lying in the $a-c$ plane and running in the crystallographic $a$-direction. Strong $L u-R u$ bonding exists as is evident by the bond length of $3.05 \AA$ which is very close to that calculated $(3.07 \AA)$ from the $\mathrm{CN} 12$ metallic radii. The boron atoms are dimerized $(d(B-B)=1.74 \mathrm{~A})$ and are located between the $\mathrm{Lu}-\mathrm{Ru}$ planes. The $\mathbf{B}_{\mathbf{2}}$ dimers are weakly coupled to form zig-zag chains running perpendicular to the metal planes (i.e., parallel to the $b$-axis). This is in contrast to the $\mathrm{AM}_{4} \mathrm{~B}_{4}$ compounds where the $\mathrm{B}_{2}$ pairs are isolated from each other.

It is clear that superconductivity arises in $\operatorname{LnRuB}_{2}$ phases from the $R u 4 d$ electrons but the $\mathrm{Ln}$ atoms also play a crucial role because of strong $\mathrm{Ln}-\mathrm{Ru}$ bonding and $\mathrm{Ln}-\mathrm{Ln}$ bonding. Superconductivity is not exhibited when $\mathrm{Ln}$ ion has a magnetic moment but then the magnetic ordering temperatures are also high (e.g., $\mathrm{Ln}=\mathrm{Tb}$, $\left.T_{m}=45.6 ; \mathrm{Ln}=\mathrm{Dy}, T_{m}=21.9 \mathrm{~K}\right) \cdot T_{m}$ values are also high in the corresponding osmium phases, $\mathrm{LnOsB}_{2}\left(\mathrm{Ln}=\mathrm{Tb}, T_{m}=39.2 \mathrm{~K}\right)$ but the $T_{c}$ values are low for non-magnetic $\mathrm{Ln}$ (e.g., $\mathrm{Ln}=\mathrm{Lu}, T_{c}=2 \cdot 7 ; \mathrm{Y}, T_{c}=2 \cdot 2 \mathrm{~K}$ ).

\subsection{Compounds with $A M_{3} B_{2}$ stoichiometry}

Isotypic series of compounds with $\mathrm{ACo}_{3} \mathrm{~B}_{2}$ stoichiometry were first prepared and characterized by Kuz'ma et al (1969). Later studies revealed that a large number of compounds with the formula $\mathrm{AM}_{3} \mathrm{~B}_{2}, \mathrm{~A}=$ rare earth, $\mathrm{Zr}, \mathrm{Hf}, \mathrm{Th}, \mathrm{Ba} ; \mathrm{M}=\mathrm{Co}, \mathrm{Ru}, \mathrm{Rh}$, $\mathrm{Os}, \mathrm{Ir}, \mathrm{Pt}$ do form. The structure types adopted by them are: (i) hexagonal $\mathrm{CeCo}_{3} \mathrm{~B}_{2}$ type, (ii) monoclinic ErIr ${ }_{3} \mathrm{~B}_{2}$-type, (iii) hexagonal $\mathrm{Ba}_{0.67} \mathrm{Pt}_{3} \mathrm{~B}_{2}$-type, and (iv) orthorhombic (?) $\mathrm{YOs}_{3} \mathrm{~B}_{2}$-type. In the $\mathrm{CeCo}_{3} \mathrm{~B}_{2}$-type structure the $\mathrm{B}$ atoms are isolated from each other and there exists an interpenetrating network of $A$ and $M$ atom clusters. The ErIr ${ }_{3} \mathrm{~B}_{2}$ and $\mathrm{Ba}_{0.67} \mathrm{Pt}_{3} \mathrm{~B}_{2}$ structures are distorted derivatives of the hexagonal $\mathrm{CeCO}_{3} \mathrm{~B}_{2}$ structure. The fact that the latter structure is not conducive to high temperature superconductivity can be seen from the following data: (i) for $\mathrm{AM}_{3} \mathrm{~B}_{2}$, $\mathrm{A}=$ rare earth; $\mathrm{M}=\mathrm{Ru}, \mathrm{Os}, \mathrm{Rh}$ and $\mathrm{Ir}, T_{\mathrm{c}}$ does not exceed $4.6 \mathrm{~K}(\mathrm{Ku}$ et al $1980 ; \mathrm{Ku}$ and Meisner 1981; Malik et al 1982; Dhar et al 1983); (ii) $\operatorname{LnM}_{3} B_{2}(M=R h$, Ir) with the 
$\operatorname{ErIr}_{3} \mathrm{~B}_{2}$ structure do not have $T_{c}$ above $1.2 \mathrm{~K}$ (Ku and Meisner 1981); (iii) for $\mathrm{A}_{0.67} \mathrm{Pt}_{3} \mathrm{~B}_{2}$ the $T_{\mathrm{c}}$ are 1.6, 2.8 and $5.6 \mathrm{~K}$ for $\mathrm{A}=\mathrm{Ca}, \mathrm{Sr}$ and $\mathrm{Ba}$ (Shelton 1978) and (iv) $\mathrm{AOs}_{3} \mathrm{~B}_{2}, \mathrm{~A}=\mathrm{Th}, T_{c}=3 \mathrm{~K} ; \mathrm{A}=\mathrm{Y}, T_{c}=6 \mathrm{~K}(\mathrm{Ku} \mathrm{1980)}$.

\section{Ternary carbides}

Of the known ternary carbides, molybdenum borocarbide, $\mathrm{Mo}_{2} \mathrm{BC}$ and aluminocarbide, $\mathrm{Mo}_{3} \mathrm{Al}_{2} \mathrm{C}$ merit attention since they exhibit superconductivity with $T_{c}$ of 7.5 and $10 \mathrm{~K}$ respectively. $\mathrm{Mo}_{2} \mathrm{BC}$ has an orthorhombic symmetry (space group, cmcn) with $a=3.086, b=17.35$ and $c=3.047 \AA$ and the structure can be described as a combination of boride and carbide subcells (figure 14). The carbon atoms are located at the centre of $\mathrm{Mo}_{6}$ distorted octahedra, which share edges to form layers. The octahedron layers are separated from each other by boron layers, the boron atoms forming zig-zag chains which pass through the trigonal prisms of the Mo-atoms. Recently Lejay et al $(1981 \mathrm{a}, \mathrm{b})$ synthesized $\mathrm{Mo}_{2} \mathrm{BC}$ single crystals and examined their properties. They also found that transition elements $\mathrm{Zr}, \mathrm{Nb}, \mathrm{Rh}, \mathrm{Hf}$, Ta and $\mathrm{W}$ can be substituted to a significant extent $\left(x=0 \cdot 15-1 \cdot 1\right.$ in $\left.\mathbf{M o}_{2-x} \mathbf{M}_{x} \mathbf{B C}\right)$ in samples prepared in polycrystalline form by arc melting techniques. While the $T_{c}$ decreased with increase in $x$ for all the alloys, the Rh-containing alloy exhibited an increase of $T_{c}$ (up to $9 \mathrm{~K}$ ) and $H_{c 2}(27 \mathrm{kOe}$ for $x=0)$ and then a decrease (to $6.7 \mathrm{~K}$ ) for $x$ ranging from $0-0.3$. The authors found a good correlation of $T_{c}$ with the molar volume and valence electron concentration in all the alloys studied.

$\mathrm{Mo}_{3} \mathrm{Al}_{2} \mathrm{C}$ has a cubic $\beta-\mathrm{Mn}$ structure with $a=6.867 \AA$. The phase, along with the other $\mathrm{M}_{3} \mathrm{Al}_{2} \mathrm{C}(\mathrm{M}=\mathrm{Ti}, \mathrm{V}, \mathrm{Cr}, \mathrm{Nb}$ and $\mathrm{Ta})$, was first synthesized by Jeitschko et al (1963) and later Johnston et al (1964) discovered it to be superconducting with a $T_{c}$ of $10 \mathrm{~K}$. Similar to the $\mathrm{Mo}_{2} \mathrm{BC}$, the $\mathrm{C}$ atoms are located in an octahedra of Mo-atoms in $\mathrm{Mo}_{3} \mathrm{Al}_{2} \mathrm{C}$ and the $\mathrm{Mo}-\mathrm{C}$ distance of $2 \cdot 14 \mathrm{~A}$ indicates strong covalent bonding. The

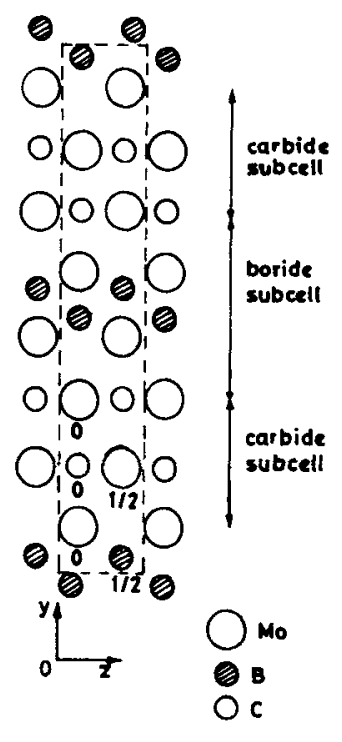

Figure 14. Crystal structure of $\mathrm{Mo}_{2} \mathrm{BC}$. Projection of the ZOY plane is shown. 
$\beta$-Mn structure is without doubt conducive to high $T_{c}$ superconductivity since other phases with $\mathrm{M} \neq \mathrm{Mo}$, crystallizing in a hexagonal structure do not have a $T_{c}$ above $4 \cdot 2 \mathrm{~K}$.

\section{Ternary silicides}

Ternary silicides have attracted wide attention in recent years and a variety of phases with different stoichiometries have been synthesized and studied. The important systems are: (i) $\mathrm{LnMSi}$, ( $\mathrm{Ln}=$ rare earth or $\mathrm{Y} ; \mathrm{M}=\mathrm{Rh}$ and $\mathrm{Ir}$ ) with the TiNiSi structure for $\mathrm{Ln}=\mathrm{Gd} \rightarrow \mathrm{Er}$ and $\mathrm{Y}$ and with the $\mathrm{ZrOS}$ (or $\mathrm{SrSi}_{2}$ :Cubic) structure for LaRhSi and LnIrSi ( $\mathrm{Ln}=\mathrm{La} \rightarrow \mathrm{Nd}$ ) (Chevalier et al 1982a,b; Klepp and Parthe 1982); (ii) $\mathrm{LnMSi}_{2}$ ( $\mathrm{Ln}=\mathrm{La} \rightarrow \mathrm{Gd} ; \mathrm{M}=\mathrm{Rh}$ and Ir) with the orthorhombic $\mathrm{CeNiSi}{ }_{2}$ structure (Chevalier et al 1982c,d; Chevalier et al 1983); (iii) $\mathrm{LnRh}_{2} \mathrm{Si}_{2}(\mathrm{Ln}=\mathrm{La} \rightarrow \mathrm{Er}$; Y) with the tetragonal $\mathrm{ThCr}_{2} \mathrm{Si}_{2}$ structure (Ballestraci 1976; Chevalier et al 1983; Felner and Nowik 1983); (iv) $\mathrm{Ln}_{2} \mathrm{RhSi}_{3}(\mathrm{Ln}=\mathrm{La} \rightarrow \mathrm{Er}$; Y) with a hexagonal structure (Chevalier et al 1982c,d; Chevalier et al 1983); (v) $\mathrm{LnRu}_{3} \mathrm{Si}_{2}(\mathrm{Ln}=\mathrm{La} \rightarrow \mathrm{Yb}$; $\mathrm{Y}$ and U) with the hexagonal $\mathrm{LaRu}_{3} \mathrm{Si}_{2}$ structure (Barz 1980; Vandenberg and Barz 1980) and $\mathrm{LnRh}_{3} \mathrm{Si}_{2}(\mathrm{Ln}=\mathrm{La} \rightarrow \mathrm{Er}$ and $\mathrm{Y})$ with hexagonal $\mathrm{CeCo}_{3} \mathrm{~B}_{2}$-type structure (Chevalier et al 1981); (vi) $\mathrm{Ln}_{2} \mathrm{M}_{3} \mathrm{Si}_{5}(\mathrm{Ln}=\mathrm{Sm} \rightarrow \mathrm{Lu} ; \mathrm{Sc}$ and $\mathrm{Y} ; \mathrm{M}=\mathrm{Fe}$, Ru and Os) with the tetragonal $\mathrm{Sc}_{2} \mathrm{Fe}_{3} \mathrm{Si}_{5}$-structure (Braun 1980, 1981; Braun et al 1981) and $\mathrm{Ln}_{2} \mathrm{Rh}_{3} \mathrm{Si}_{5}$ $\left(\mathrm{Ln}=\mathrm{La} \rightarrow \mathrm{Er}\right.$ and $\mathrm{Y}$ ) with the orthorhombic $\mathrm{U}_{2} \mathrm{Co}_{3} \mathrm{Si}_{5}$-type structure (Chevalier et al 1982e) and (vii) $\mathrm{Sc}_{5} \mathrm{M}_{4} \mathrm{Si}_{10}(\mathrm{M}=\mathrm{Co}, \mathrm{Rh}, \mathrm{Ir})$ and $\mathrm{Ln}_{5} \mathrm{Ir}_{4} \mathrm{Si}_{10}(\mathrm{Ln}=\mathrm{Dy} \rightarrow \mathrm{Lu}, \mathrm{Y})$ with the tetragonal $\mathrm{Sc}_{5} \mathrm{Co}_{4} \mathrm{Si}_{10}$-type structure (Braun et al 1980; Braun and Segre 1980, 1981). Of the above, many phases are superconducting for $\mathrm{Ln}=\mathrm{Sc}, \mathrm{Y}, \mathrm{La}, \mathrm{Lu}$, but high $T_{c}$ superconductivity is realized only in the phases $\mathrm{LaRu}_{3} \mathrm{Si}_{2}\left(T_{c}=7.6 \mathrm{~K}\right), \mathrm{Lu}_{2} \mathrm{Fe}_{3} \mathrm{Si}_{5}$ $\left(T_{c}=6.1 \mathrm{~K}\right)$ and $\mathrm{Sc}_{5} \mathrm{M}_{4} \mathrm{Si}_{10}\left(\mathrm{M}=\mathrm{Rh}\right.$ and $\left.\mathrm{Ir} ; T_{c}=8.5-8.6 \mathrm{~K}\right)$. It is significant to note that $\mathrm{LaRu}_{3} \mathrm{Si}_{2}$ is a distorted version of the hexagonal $\mathrm{CeCo}_{3} \mathrm{~B}_{2}$ structure and contains triangular $\mathrm{Ru}_{3}$ clusters. On the other hand, the $\mathrm{LnRh}_{3} \mathrm{Si}_{2}$ phases crystallize with the undistorted $\mathrm{CeCo}_{3} \mathrm{~B}_{2}$-structure and the latter, as noted earlier, is not very conducive to high $T_{c}$ superconductivity. Hence it is not surprising that $\mathrm{LnRh}_{3} \mathrm{Si}_{2}(\mathrm{Ln}=\mathrm{La}$ and $\mathrm{Y})$ are not superconducting above $0.05 \mathrm{~K}$ (Chevalier et al 1981).

\subsection{Primitive tetragonal $\mathrm{Sc}_{2} \mathrm{Fe}_{3} \mathrm{Si}_{5}$ and $\mathrm{Sc}_{5} \mathrm{Co}_{4} \mathrm{Si}_{10}$ structures}

Isostructural primitive tetragonal phases of the formula $\operatorname{Ln}_{2} \mathrm{M}_{3} \mathrm{Si}_{5}$ exist for the following combinations: $\mathrm{M}=\mathrm{Fe}, \mathrm{Ln}=\mathrm{Sm} \rightarrow \mathrm{Lu}, \mathrm{Y}, \mathrm{Sc} ; \mathrm{M}=\mathrm{Ru}$ and $\mathrm{Os}, \mathrm{Ln}=\mathrm{Lu}, \mathrm{Y}$ and $\mathrm{Y}_{2} \mathrm{Re}_{3} \mathrm{Si}_{5}$. The $a$ and $c$ values respectively are $\sim 10.3$ and $\sim 5.3 \mathrm{~A}$. One interesting aspect is that the Fe-containing phases with $\mathrm{Ln}=\mathrm{Lu}, \mathrm{Sc}$ and $\mathrm{Y}$ exhibit $T_{\mathrm{c}}$ of $6 \cdot 1,4 \cdot 5$ and $2.4 \mathrm{~K}$ respectively, relatively high values for an iron ( $3 d$ metal)-based compounds. Remarkably enough, reentrant superconductivity has been discovered in $\mathrm{Tm}_{2} \mathrm{Fe}_{3} \mathrm{Si}_{5}$ with $T_{c 1}=1.3 \mathrm{~K}$ and $T_{c 2}=1.1 \mathrm{~K}$ (table 4) (Segre and Braun 1981). Mössbauer studies of $\mathrm{Ln}_{2} \mathrm{Fe}_{3} \mathrm{Si}_{5}$ (Cashion et al 1980, 1981) have shown that the magnetic moment on $\mathrm{Fe}$ atoms (iron occupies two sets of point positions in the structure) is less than $0.03 \mu_{B}$ and indicate that the iron $3 d$-electrons are non-magnetic and participate in strong bonding with $\mathrm{Si}$ atoms. When $\mathrm{Fe}$ is replaced by the isoelectronic $\mathrm{Ru}$ or $\mathrm{Os}$, superconductivity disappears for $\mathrm{Ln}=\mathrm{Lu}$ and $\mathrm{Y}$ and this fact raises the important question whether the $\mathrm{Fe}-3 d$ electrons participate in superconductivity or not. When $\mathrm{Ln}$ is a magnetic rare earth, the Fe-containing phases exhibit antiferromagnetism with $T_{N} \sim 10 \mathrm{~K}$. 
Primitive tetragonal $\mathrm{Ln}_{5} \mathrm{M}_{4} \mathrm{Si}_{10}$ compounds with $a \sim 12 \AA$ and $c \sim 3.9 \AA$ form for $\mathrm{Ln}=\mathrm{Sc}$ and $\mathrm{M}=\mathrm{Co}, \mathrm{Rh}$ and $\mathrm{Ir}$ and for $\mathrm{Ln}=\mathrm{Dy} \rightarrow \mathrm{Lu}, \mathrm{Y}$ for $\mathrm{M}=\mathrm{Ir}$. In the prototype compound $\mathrm{Sc}_{5} \mathrm{Co}_{4} \mathrm{Si}_{10}$, the $\mathrm{Co}$ and $\mathrm{Si}$ atoms form planar nets of hexagons and pentagons which are connected along (001) axis via Co-Si-Co zig-zag chains to form a three-dimensional network. The hexagon-pentagon layers are separated by layers of Sc atoms and the Co atoms are isolated from each other. The Sc-containing phases are superconductors with $T_{\mathrm{c}}=5,8.5$ and $8.5 \mathrm{~K}$ for $\mathrm{M}=\mathrm{Co}, \mathrm{Rh}$ and $\mathrm{Ir}$. The $\mathrm{Ir}$ containing phases with $\mathrm{Ln}=\mathrm{Lu}$ and $\mathrm{Y}$ are also superconducting $\left(T_{c}=3.8\right.$ and $\left.3 \mathrm{~K}\right)$ whereas those with $\mathrm{Ln}=$ magnetic ions, are magnetic at low temperatures. It is interesting to note that the Co compound has a fairly high $T_{\text {c }}$ and $\chi-T$ data reveal that the Co atoms do not carry any localized magnetic moment (Braun and Segre 1981); the quenching of the moment correlates well with the short (covalent) $\mathrm{Co}-\mathrm{Si}$ and $\mathrm{Si}-\mathrm{Si}$ interatomic distances in the structure.

\section{Ternary germanides}

Well-defined rare earth ternary germanides are few in number and have only recently been isolated and studied. They are: (i) $\mathrm{Y}_{5} \mathrm{M}_{4} \mathrm{Ge}_{10}(\mathrm{M}=\mathrm{Ir}$ and Os) with the tetragonal $\mathrm{Sc}_{5} \mathrm{Co}_{4} \mathrm{Si}_{10}$-type structure (Braun and Segre 1980, 1981; Braun et al 1980). For $\mathrm{M}=\mathrm{Os}, T_{\mathrm{c}}=8.7 \mathrm{~K}$ whereas for $\mathrm{M}=\mathrm{Ir}, T_{c}$ is only $2.6 \mathrm{~K}$. (ii) $\operatorname{Ln}_{3} \mathrm{M}_{4} \mathrm{Ge}_{13}$ $\left(\mathrm{Ln}=\mathrm{Ce} \rightarrow \mathrm{Lu}, \mathrm{Y} ; \mathrm{M}=\mathrm{Ru}\right.$ and $\mathrm{Os}$ ) with the primitive cubic $\mathrm{Pr}_{3} \mathrm{Rh}_{4} \mathrm{Sn}_{13}$-type structure (Segre et al 1981). The lattice constants are $\sim 9 \AA$ and when $L n=Y$ and $L u$, the phases are superconducting with $T_{\mathrm{c}}$ less than $3.9 \mathrm{~K}$. When the $\mathrm{Ln}$ is a magnetic ion, the compounds order magnetically with $T_{m}$ as high as $16 \mathrm{~K}$. (iii) $\mathrm{LnM}_{2} \mathrm{Ge}_{2}$ $(\mathrm{Ln}=\mathrm{La}, \mathrm{Yb} ; \mathrm{M}=\mathrm{Pd}, \mathrm{Pt})$ with the tetragonal $\mathrm{ThCr}_{2} \mathrm{Si}_{2}$ structure (Hull et ai 1981). $T_{c}$ is around $1 \mathrm{~K}$ for $\mathrm{Ln}=\mathrm{La}, \mathrm{Yb}$ and $\mathrm{M}=\mathrm{Pd}$ whereas $\mathrm{LaPl}_{2} \mathrm{Ge}_{2}$ has a $T_{c}$ of $0.55 \mathrm{~K}$. (iv) $\mathrm{LnMGe}(\mathrm{M}=\mathrm{Co}, \mathrm{Ni}$; $\mathrm{Ln}=\mathrm{Gd} \rightarrow \mathrm{Lu}, \mathrm{Y}$; Sc; $\mathrm{M}=\mathrm{Rh}, \mathrm{Pd}$, Ir, Pt; $\mathrm{Ln}=\mathrm{La} \rightarrow \mathrm{Tm} ; \mathrm{Y} ; \mathrm{Sc})$. The phases adopt either the orthorhombic TiNiSi- or $\mathrm{CeCu}_{2^{-}}$ type or hexagonal $\mathrm{ZrNiAl}\left(\mathrm{Fe}_{2} \mathrm{P}\right)$-type or tetragonal LaPtSi-type structure (Hovestreydt et al 1982).

\section{Ternary stannides}

A large number of ternary stannides, $\mathrm{AM}_{x} \mathrm{Sn}_{y}$, have been isolated and studied in recent years with the specific aim of examining the interplay between superconductivity and magnetic order. An advantage in these stannides is that most of them are cubic systems and large single crystals can be grown employing metallic tin as flux. The ideal stoichiometry established by single crystal $x$-ray data is $\mathrm{Ln}_{3} \mathrm{Rh}_{4} \mathrm{Sn}_{13}(\mathrm{Ln}=\operatorname{Pr}$ and $\mathrm{Yb})$ and the phases are isotypic with the germanides, $\operatorname{Ln}_{3} \mathrm{M}_{4} \mathrm{Ge}_{13}(\mathrm{M}=\mathrm{Ry}$ and $\mathrm{Os})$. However, the formula is usually written as $A_{1.00} M_{x} S_{y}$ with $x=1-1.5$ and $y=3 \cdot 1-4 \cdot 5$. Primitive cubic $\operatorname{Pr}_{3} \mathrm{Rh}_{4} \mathrm{Sn}_{13}$-type structure (phase I with $a \sim 9.7 \AA$ ) is encountered for $\mathrm{A}=\mathrm{Ca}, \mathrm{Sr}$ with $\mathrm{M}=\mathrm{Co} ; \mathrm{A}=\mathrm{Ca} ; \mathrm{Sr}, \mathrm{Ln}$ (rare earth) and Th with $\mathrm{M}=\mathrm{Ru}$ and Ir; $\mathrm{A}=\mathrm{La}$ with $\mathrm{M}=\mathrm{Ru}$ and $\mathrm{A}=\mathrm{Ca}$ with $\mathrm{M}=\mathrm{Pt}$ (Espinosa 1980; Espinosa et al 1980; Remeika et al 1980; Vandenberg 1980; Hodeau et al 1980; Cooper 1980). Tetragonal (phase II with $a \sim 13.7 ; c \sim 9.7 \AA$ ) stannides are found for $\operatorname{LnRu}_{x} \mathrm{Sn}_{y} . \mathrm{Ln}=\mathrm{Er}, \mathrm{Lu}$; $\mathrm{ErCo}_{x} \mathrm{Sn}_{y} ; \mathrm{LnRh}_{x} \mathrm{Sn}_{y}, \mathrm{Ln}=\mathrm{Sc}, \mathrm{Y}, \mathrm{Ho} \rightarrow \mathrm{Lu}$ and $\mathrm{LnIr}_{x} \mathrm{Sn}_{y}, \mathrm{Ln}=\mathrm{Sc}, \mathrm{Er} \rightarrow \mathrm{Lu}$ (Remeika et al 1980; Espinosa 1980; Cooper 1980; Andres et al 1981; Chenavas et al 
1981). Fcc (phase III with $a \sim 13.7 \AA$ ) stannides are found for $\operatorname{LnM}_{x} \operatorname{Sn}_{y}, \operatorname{Ln}=\mathrm{Y}, \mathrm{Er}$ and $\mathrm{M}=\mathrm{Ru}$ and $\mathrm{Os} ; \mathrm{LnRh}_{x} \mathrm{Sn}_{y}, \mathrm{Ln}=\mathrm{Tb} \rightarrow \mathrm{Tm} ; \mathrm{LnIr}_{x} \mathrm{Sn}_{y}, \mathrm{Ln}=\mathrm{Y}, \mathrm{Gd} \rightarrow \mathrm{Yb}$ (Espinosa et al 1980; Remeika et al 1980; Espinosa 1980; Cooper 1980; Chenavas et al 1981; Lambert et al 1981). The lattice parameters of phases I, II and III are related: $\sqrt{2} a(\mathrm{I}) \approx a(\mathrm{III}) \approx a(\mathrm{II}) \approx(\mathrm{c}(\mathrm{II}) / 2)$. Hence the structure of phase $\mathrm{I}$, which is known in detail, might be related to the phases II and III.

The $\operatorname{Pr}_{3} \mathrm{Rh}_{4} \mathrm{Sn}_{13}$ structure with 2 formula units per unit cell has a number of interesting features: (i) the tin atoms occupy two different types of positions: $2 \mathrm{Sn}$ (1) atoms per unit cell form a bcc sublattice and appear to be cationic in character; the remaining 24 tin atoms, $\operatorname{Sn}(2)$, are anionic in nature and coordinate the $\operatorname{Sn}(1), \operatorname{Pr}$ and $\mathrm{Rh}$ atoms. The formula can then be written as $\operatorname{Sn}(1) \operatorname{Pr}_{3} \operatorname{Rh}_{4} \operatorname{Sn}(2)_{12}$. Mössbauer studies have corroborated the existence of two kinds of Sn atoms in the structure (Shenoy et al 1980), (ii) the Pr and Sn(1) atoms together form the beta-W (A15) structure in which nonintersecting and mutually perpendicular chains of Pr atoms run across the cell faces (figure 15). However, the $\mathrm{Pr}-\mathrm{Pr}$ distances are large. The $\mathrm{Rh}$ atoms form an interpenetrating simple cubic array and one $\mathrm{Rh}_{8}$ cube is situated at the centre of each A15 unit cell as shown in figure 15 . The $\mathrm{Sn}(1) \mathrm{Pr}_{3} \mathrm{Rh}_{4}$ sublattice resembles the channeltype structure of $\mathrm{Na}_{x} \mathrm{Pt}_{3} \mathrm{O}_{4}$. However, the $\mathrm{Rh}-\mathrm{Rh}$ distances are large (much greater than the intermetallic distance in $\mathrm{Rh}$ metal) and there is only weak Pr-Rh bonding. Thus, there are no $\operatorname{Sn}(1)-\operatorname{Sn}(1), \operatorname{Pr}-\operatorname{Pr}$ or Rh-Rh clusters. Hodeau et al (1980) have shown that $\mathrm{Yb}$ and $\mathrm{Sn}(1)$ atoms in $\mathrm{Sn}(1) \mathrm{Yb}_{3} \mathrm{Rh}_{4}-\mathrm{Sn}(2)_{12}$ show mutual substitutional disorder on the $\mathrm{Sn}(1)$ and $\mathrm{Yb}$ sites of the structure (5.7 and 8.5 atom \% respectively). This disorder may have a significant effect on the superconducting and other properties of the phase I stannides, (iii) the $\operatorname{Sn}(2)$ atoms effectively isolate each Pr and $\mathrm{Rh}$ atoms from the others but they themselves form pairs with the $\operatorname{Sn}(2)-\operatorname{Sn}(2)$ distance slightly less or almost equal to that encountered in tin metal. Hence the phase I stannides might, therefore, be expected to exhibit physical properties typical of sp-band metals. Also, since the A or Ln element occupies a distinct position in the crystal lattice, those ions which support a magnetic moment may exhibit magnetic ordering at low temperatures.

Phase I (primitive cubic) stannides exhibit superconductivity for $A=\mathrm{Ca}, \mathrm{Sr}, \mathrm{La}, \mathrm{Th}$ or $\mathrm{Yb}$ (table 5) with a high $T_{c}$ of $8.7 \mathrm{~K}$ for the $\mathrm{CaRh}_{1.2} \mathrm{Sn}_{4.5}$. It is significant that the Cocontaining compound also exhibits a relatively high $T_{c}(5.9 \mathrm{~K})$. The $\mathrm{LnM}_{x} \mathrm{Sn}_{y}$ compounds with the phase II and III structures show superconductivity when the rare earth is nonmagnetic. $\mathrm{ErRh}_{1 \cdot 1} \mathrm{Sn}_{3 \cdot 6}$ (Remeika et al 1980; Shenoy et al 1980; Ott et al 1981) and $\operatorname{ErOs}_{x} \mathrm{Sn}_{y}$ (Espinosa et al 1980) have been found to exhibit a reentrant behaviour at zero applied magnetic field and $\mathrm{TmRh}_{1.3} \mathrm{Sn}_{4}$ in applied fields greater than $1.2 \mathrm{kOe}$ (Lambert et al 1981). Recent studies on phase III $\mathrm{LnOs}_{x} \mathrm{Sn}_{y}$ by Fisk et al (1982)

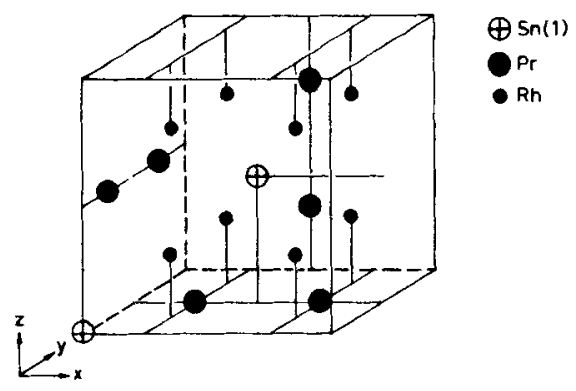

Figure 15. Structure of $\mathrm{Sn}(1)$ $\operatorname{Pr}_{3} \mathrm{Rh}_{4} \operatorname{Sn}(2)_{12}$ showing the $\operatorname{Sn}(1) \mathrm{Pr}_{3} \mathrm{Rh}_{4}$ sublattice. The disposition of the $\mathrm{Sn}(2)$ atoms not shown. These exist as pairs with interatomic distance similar to that in Sn metal (after Hodeau et al 1980). For discussion see text. 
Table 5. Structure, $T_{\mathrm{c}}$ and $T_{m}$ data of select $\mathrm{AM}_{x} \mathrm{Sn}_{y}$ stannides

\begin{tabular}{|c|c|c|c|c|c|c|}
\hline A & $\mathbf{M}$ & Sn & $a_{o}(\mathrm{~A})$ & $c_{0}(\mathrm{~A})$ & $T_{c}(\mathbf{K})$ & $T_{m}(\mathbf{K})$ \\
\hline \multicolumn{7}{|c|}{ Phase I compounds (Prim. cubic; $\mathrm{Pr}_{3} \mathrm{Rh}_{4} \mathrm{Sn}_{13}$-type structure) } \\
\hline $\mathrm{Ca}$ & $\mathbf{R h}_{1 \cdot 2}$ & $\mathrm{Sn}_{4 \cdot 5}$ & $9 \cdot 702$ & - & 8.7 & - \\
\hline $\mathrm{Sr}$ & $\mathbf{R h}_{x}$ & $\mathrm{Sn}_{\mathrm{y}}$ & 9.800 & - & $4 \cdot 3$ & - \\
\hline La & $\mathbf{R h}_{x}$ & $\mathrm{Sn}_{y}$ & 9.745 & - & $3 \cdot 2$ & - \\
\hline Eu & $\mathbf{R h}_{x}$ & $\mathbf{S S}_{\mathrm{y}}$ & 9.749 & - & - & 11 \\
\hline $\mathrm{Yb}$ & $\mathrm{Rh}_{x}$ & $\mathrm{Sn}_{y}$ & $9 \cdot 676$ & - & $8 \cdot 6$ & - \\
\hline Th & $\mathrm{Rh}_{x}$ & $\mathrm{Sn}_{y}$ & 9.692 & - & 1.9 & - \\
\hline $\mathrm{Ca}$ & $\mathbf{I r}_{\boldsymbol{x}}$ & $\mathrm{Sn}_{y}^{\prime}$ & $9 \cdot 718$ & - & $7 \cdot 1$ & - \\
\hline Sr & $\operatorname{Ir}_{x}$ & $\mathrm{Sn}_{y}$ & 9.807 & - & $5 \cdot 1$ & - \\
\hline $\mathrm{Ca}$ & $\mathrm{Co}_{x}$ & $\mathrm{Sn}_{y}$ & $9 \cdot 584$ & - & 5.9 & - \\
\hline La & $\mathbf{R u}_{1 \cdot s}$ & $\mathrm{Sn}_{4.5}$ & 9.772 & - & 3.9 & - \\
\hline \multicolumn{7}{|c|}{ Phase II compounds (tetragonal structure) } \\
\hline Sc & $\mathbf{R} \mathbf{h}_{x}$ & $\mathrm{Sn}_{\mathrm{y}}$ & 13.565 & $9.558^{a}$ & $4 \cdot 5$ & - \\
\hline $\mathbf{Y}$ & $\mathrm{Rh}_{x}$ & $\mathrm{Sn}_{y}$ & $13 \cdot 772$ & $9 \cdot 707$ & $3 \cdot 2$ & - \\
\hline Er & $\mathbf{R h}_{1,1}$ & $\mathrm{Sn}_{3 \cdot 6}$ & $13 \cdot 733$ & $9 \cdot 139$ & 1.36 & $0-46^{b}$ \\
\hline Lu & $\mathbf{R h}_{1 \cdot 2}$ & $\mathrm{Sn}_{4 \cdot 0}$ & $13 \cdot 693$ & 9.648 & 40 & - \\
\hline Lu & $\mathbf{I r}_{x}$ & $\mathrm{Sn}_{y}$ & $13 \cdot 708$ & $9 \cdot 661$ & $3 \cdot 2$ & - \\
\hline \multicolumn{7}{|c|}{ Phase III compounds ( $f c c$ structure) } \\
\hline $\mathrm{Tb}$ & $\mathbf{R h}_{1 \cdot 1}$ & $\mathrm{Sn}_{3 \cdot 6}$ & $13 \cdot 774$ & - & - & 40 \\
\hline Dy & $\mathbf{R h}_{1 \cdot 1}$ & $\mathrm{Sn}_{3.6}$ & $13 \cdot 75$ & - & - & $2 \cdot 1$ \\
\hline $\mathbf{Y}$ & $\mathrm{Os}_{x}$ & $\mathrm{Sn}_{y}$ & 13.801 & - & 2.5 & - \\
\hline Gd & $\mathrm{Os}_{x}$ & $\mathrm{Sn}_{\mathrm{y}}$ & 13.773 & - & - & - \\
\hline $\mathrm{Tb}$ & $\mathrm{Os}_{1 \cdot 5}$ & $\mathrm{Sn}_{2 \cdot 6}$ & $13 \cdot 812$ & - & 1.4 & - \\
\hline Dy & $\mathrm{Os}_{1,5}$ & $\mathrm{Sn}_{2.5}$ & 13.792 & - & - & $\ldots$ \\
\hline Ho & $\mathrm{Os}_{1 \cdot 2}$ & $\mathrm{Sn}_{2 \cdot 5}$ & $13 \cdot 776$ & - & 1.4 & - \\
\hline $\mathrm{Er}$ & $\mathrm{Os}_{1.1}$ & $\mathrm{Sn}_{2 \cdot 7}$ & $13 \cdot 760$ & - & $1 \cdot 3$ & $0.5^{b}$ \\
\hline $\mathrm{Tm}$ & $\mathrm{Os}_{\mathrm{x}}$ & $\mathrm{Sn}_{y}$ & 13.744 & - & $1 \cdot 1$ & $0.6^{b}$ \\
\hline$Y$ & $\mathrm{I} r_{x}$ & $\mathrm{Sn}_{y}$ & $13 \cdot 773$ & - & $2 \cdot 2$ & - \\
\hline
\end{tabular}

a The $c_{0}$ values should be multiplied by $2 \sqrt{2}$ to obtain the true tetragonal $c$-axis values (Chenavas et al 1981).

${ }^{b}$ Re-entrant superconductor.

have shown that only superconductivity is observed for $\mathrm{Ln}=\mathrm{Tb}$ and $\mathrm{Ho}$, those of $\mathrm{Er}$ and $\mathrm{Tm}$ are reentrant superconductors whereas those of $\mathrm{Gd}$ and Dy appear to exhibit some type of short-range magnetic order at low temperatures.

In contrast to the behaviour of $\mathrm{ErRh}_{4} \mathrm{~B}_{4}$ and $\mathrm{HoMo}_{6} \mathrm{~S}_{8}$, the stannide $\mathrm{ErRh}_{1.1} \mathrm{Sn}_{3.6}$ exhibits no thermal hysteresis at the reentrant transition measured either resistively or inductively. Neutron diffraction data (Remeika et al 1980) show that even at $T=0.07 \mathrm{~K}$, true long-range order does not develop in the compound; presumably, the substitutional disorder at the Er site (by the Sn(1) atoms) may affect the integrity of the rare earth sublattice. This may also explain the sample dependence of the superconductivity and magnetic behaviour of stannides observed by Ott et al (1981). We also note from table 5 and the work of Espinosa et al (1982) that detailed studies are yet to be carried out on many of the stannide phases. 


\section{Ternary phosphides and pnictides}

\subsection{Niobium sulpho phosphide, NbPS}

Donohue and Bierstedt (1969) discovered that niobium sulphophosphide, NbPS is superconducting with a $T_{c}$ of $12.5 \mathrm{~K}$. The compound, along with the other anologues TaPS and NbPSe can be synthesized only under high pressure and high temperature conditions $\left(65 \mathrm{~kb}, 1200^{\circ} \mathrm{C}\right)$. The structure of $\mathrm{NbPS}$ is orthorhombic (space group Immm $Z=4, a=3.438, b=11.88, c=4.725 \AA$ ). The structure shows several interesting features: The $\mathrm{Nb}$ atoms are 8 -fold coordinated by $4 \mathrm{P}$ and $4 \mathrm{~S}$ atoms at the corners of a bicapped trigonal prism. The prisms share faces, in pairs, through the $4 \mathrm{P}$ atoms resulting in a short $\mathrm{Nb}-\mathrm{Nb}$ distance of $2.93 \mathrm{~A}$ (compare interatomic distance of $2.858 \mathrm{~A}$ in $\mathrm{Nb}$ metal). This distance suggests the presence of a metal-metal bond. The pairs of bicapped trigonal prisms share triangular faces in the $a$ axis direction, with this $\mathrm{Nb}-\mathrm{Nb}$ distance being that of the $a$ axis. The sulphur atoms are coordinated by $4 \mathrm{Nb}$ atoms at the corners of a distorted tetrahedron. The $\mathrm{P}$ atoms are coordinated to $4 \mathrm{Nb}$ atoms and one $\mathbf{P}$ atom. The $\mathbf{P}$ atoms form continuous strings in the $c$ axis direction with alternating short and long distances ( $2 \cdot 22$ and $2 \cdot 15 \AA$ respectively). The short distances are within the normal P-P covalent bond distances found in many other compounds. This led Donohue and Bierstedt to propose an ionic formula of the type $\left.(\mathrm{Nb})_{2}^{4+}\left(\mathrm{P}_{2}\right)^{4-} \mathrm{S}^{2-}\right)_{2}$ for the compound $\mathrm{NbPS}$ where the $\mathrm{Nb}$ is present in a $4+$ oxidation state $\left(d^{1}\right.$ system). Surprisingly enough NbPSe and TaPS, which are structurally analogous to NbPS do not exhibit superconductivity down to $1.25 \mathrm{~K}$.

\subsection{ZrRuP-type compounds}

The fact that a particular structure for a ternary system can favour the high $T_{c}$ superconductivity is nicely demonstrated by the recent work of Barz et al (1980), Müller $e t$ al (1983) and Meisner et al (1983) on the equiatomic (1:1:1) ternary transition metal phosphides and arsenides of the general formula, $M M^{\prime} X(M=\mathrm{Ti}, \mathrm{Zr}, \mathrm{Hf}, \mathrm{Nb}, \mathrm{Ta}$; $\left.M^{\prime}=\mathrm{Ru}, \mathrm{Rh}, \mathrm{Os} ; X=\mathrm{P}, \mathrm{As}\right)$. The compound ZrRuP can crystallize either in a hexagonal ZrRuSi (ordered $\mathrm{Fe}_{2} \mathrm{P}$ or $\mathrm{ZrNiAl}$, Johnson and Jeitschko 1972)-type or in the orthorhombic TiNiSi-type (ordered $\mathrm{Co}_{2} \mathbf{P}$ or anti $\mathrm{PbCl}_{2}$, Shoemaker and Shoemaker 1965). Hexagonal $\mathrm{ZrRuP}$ and $\mathrm{ZrRuAs}$ show a $T_{c}$ of 13 and $11.7 \mathrm{~K}$ (onset temperatures are 13.5 and $11.9 \mathrm{~K}$ ) respectively whereas the orthorhombic $\mathrm{ZrRuP}$ exhibits a low $T_{c}$ of $3.46 \mathrm{~K}$ (onset at $3.82 \mathrm{~K}$ ). Detailed studies are yet to be made on many of the above phases but the available data reveal that the orthorhombic structure is adopted by the compounds with $\mathrm{M}=\mathrm{Nb}$, Ta and the hexagonal arsenide phases are metastable at low temperatures. The $T_{c}$ data are summarised in table 6 .

An important structural feature of the hexagonal ZrRuP (space group, P62 m; $Z=3$ ) over that of the orthorhombic polymorph (space group, Pnam; $Z=4$ ) is the layered structure of the $\mathrm{Zr}$ and $\mathrm{Ru}$ atoms (each layer, parallel to the $x-y$ plane and separated by a distance of $c / 2$, is occupied by either $\mathrm{Zr}$ and $\mathrm{P}$ atoms or $\mathrm{Ru}$ and $\mathrm{P}$ atoms only) and the existence of $\mathrm{Ru}_{3}$-triangular clusters (short $\mathrm{Ru}$ - $\mathrm{Ru}$ distances, $2.63 \AA$; figure 16). In contrast, the orthorhombic structure has layers which are filled with $\mathrm{Zr}$ and $\mathrm{Ru}$ atoms and these layers are all equivalent; also, there do not exist the $R u_{3}$-clusters (Müller et al 1983). Recent heat capacity data (Stewart et al 1982) on the superconducting hexagonal phosphides show that the density of states at the Fermi level is not 
Table 6. $T_{\mathrm{c}}$ data on equiatomic $\mathrm{MM}^{\prime} \mathrm{X}$ ternary pnictides*

\begin{tabular}{|c|c|c|c|c|c|}
\hline \multicolumn{4}{|c|}{ Hexagonal structure $\left(\mathrm{Fe}_{2} \mathrm{P}-\right.$ type $)$} & \multicolumn{2}{|c|}{$\begin{array}{c}\text { Orthorhombic } \\
\text { structure } \\
\left(\mathrm{Co}_{2} \mathrm{P} \text {-type }\right)\end{array}$} \\
\hline Phase & $T_{c}(\mathbf{K})$ & Phase & $T_{\varepsilon}(\mathrm{K})$ & Phase & $T_{c}(\mathrm{~K})$ \\
\hline TiRuP & $1 \cdot 3$ & .. & - & ZrRuP $P^{\ddagger}$ & $3 \cdot 46$ \\
\hline ZrRuP** & $13 \cdot 0$ & ZrRuAs & $11 \cdot 7$ & ZrRhP & $<1 \cdot 1$ \\
\hline HfRuP & 109 & HfRuAs & 4.9 & NbRuP & - \\
\hline TiOsP & $1 \cdot 2$ & - & -- & NbRhP & 4.08 \\
\hline ZrOsP & 7.4 & $\mathrm{ZrOsAs}$ & 8.0 & TaRuP & - \\
\hline HfOsP & $6 \cdot 1$ & HfOsAs & $3 \cdot 2$ & TaRhP & $4 \cdot 41$ \\
\hline
\end{tabular}

* The phases with $\mathrm{M}^{\prime}=\mathrm{Fe}, \mathrm{Co}, \mathrm{Ni}$ exist and crystallize in the $\mathrm{Co}_{2} \mathrm{P}$-structure (Rundqvist and Nawapong 1966; Rundqvist and Tansuriwongs 1967) but do not exhibit superconductivity. ** $a=6.459(6) ; c=3.778(4) \mathrm{A}$

$\ddagger a=6.4169(6) ; b=7.3215(8): c=3.8623(4) \mathrm{A}$

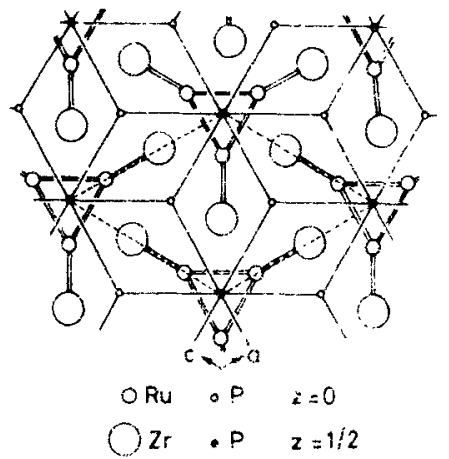

Figure 16. Projection of the ZrRuP structure along the hexagonal $c$ axis. Double lines represent the metallic bonding of the $R u-Z r$ chains and $R \mathbf{u}-\mathbf{R u}$ triangular clusters and the dashed line indicates the boundary of the hexagonal unit cell.

particularly large $\left(0 \cdot T h \pm 0.15\right.$ states $/ \mathrm{eV}$-atom) for ZrRuP with a $T_{c}$ of $13 \mathrm{~K}$ and compare, 1.08 for Ru metal with a $T_{c}$ of $0.5 \mathrm{~K}$ ) and hence the high $T_{c}$ must be due to increased elcctron-phonon interaction in the ternary system.

\subsection{Pnictides of the type $\operatorname{LnM}_{4} X_{12}$}

Ternary pnictides of the formula, $\mathrm{LnM}_{4} X_{12}$, where $\mathrm{Ln}=$ rare earth or $\mathrm{Th} ; \mathrm{M}=\mathrm{Fe}, \mathrm{Ru}$ and $O s$ and $X=P, A s$ and $S b$, represent a group of isostructural compounds with a $b c c$ structure with a varying from $7 \cdot 8$ to $9 \cdot 1 \mathrm{~A}$ (space group, $\operatorname{Im} 3 ; Z=2$; density $5-8 \mathrm{~g} / \mathrm{cc}$ ). A total of 42 compounds have been synthesized by Jeitschko and coworkers (Jeitschko and Braun 1977; Braun and Jeitschko 1980a,b,c). Due to the existence of strong X-X bonding to give rise $10 X_{4}$ groups, the phases can be considered to be metal excess ternary systems and interesting physical properties can be expected. Indeed, Meisner (1981) discovered superconductivity in the phosphides, $\mathrm{LaM}_{4} \mathrm{P}_{12}\left(\mathrm{M}=\mathrm{Fe}, T_{c}=4.1 \mathrm{~K}\right.$; $\mathrm{M}=\mathrm{Ru}, T_{c}=7.2 \mathrm{~K}$ ). Detailed studics have not yet been carried out.

In the $\mathrm{LaFe}_{4} \mathrm{P}_{12}$ structure, the Fe atom has an octahedral coordination and the $\mathrm{La}$ atom has a 12-fold (nearly icosahedral) coordination. Each P atom is surrounded by 
two other $\mathrm{P}$ and two Fe atoms forming a distorted tetrahedron with an La atom outside one face of the tetrahedron. The $\mathrm{FeP}_{6}$ octahedra share all their corners with adjacent octahedra and thus the $\mathrm{Fe}: \mathrm{P}$ ratio is $1: 3$. The octahedra are rotated in such a way that for every 4 octahedra, one large void is formed and this is filled by the La atoms (figure 17). Also, rotation of the octahedra permits a close approach of the $\mathbf{P}$ (or As or $\mathrm{Sb}$ ) atoms which thereby form rectangular, nearly quadratic, four-membered $\left(\mathrm{P}_{4}\right)$ rings (see figure 17a). The Fe or $\mathrm{La}$ atoms do not form clusters and the interatomic distances are large $(\mathrm{Fe}-\mathrm{Fe} \sim 3.9 \AA$ ); La-La $\sim 6.8 \AA$ ). However, significant bonding exists between the metal atoms and $P$ and, also between the $P$ atoms. Jeitschko and Braun (1977) suggested an ionic formula $\mathrm{Ce}^{4+}\left(\right.$ or $\left.\mathrm{Th}^{4+}\right)\left(\mathrm{FeP}_{3}\right)_{4}^{1-}$ or $\mathrm{Ce}^{4+} \mathrm{Fe}_{4}^{2+}\left(\mathrm{P}_{4}\right)_{3}^{4-}$ for the Ce-containing phosphide and also proposed a one-electron energy band model for the $\mathrm{LaFe}_{4} \mathrm{P}_{12}$-type compounds. According to the latter, the conduction band is mainly composed of Fe-metal $3 d$ and/or $4 s, 4 p$ bands and assuming an electronic charge transfer from $\mathrm{Ln}$ atoms, the band is partially filled for $\mathrm{Ln}^{3+}$ whereas, it is completely filled for $\mathrm{Ln}=\mathrm{Ce}^{4+}$ or $\mathrm{Th}^{4+}$. The latter compounds should be semiconductors whereas the $\mathrm{La}^{3+}$ compound should be metallic. This is in accord with the preliminary observed data in that $\mathrm{CeFe}_{4} \mathrm{P}_{12}$ did not show any magnetic or superconducting transition above $0.35 \mathrm{~K}$. Measurements by Meisner (1981) showed that $\operatorname{Ln} \mathrm{M}_{4} \mathrm{P}_{12}$ with $\mathrm{Ln}=\mathrm{Pr}$ and $\mathrm{Nd}$ and $\mathrm{M}=\mathrm{Fe}$ and $\mathrm{Ru}$ exhibit magnetic transitions at or below $1.5 \mathrm{~K}$.

Recent Mössbauer studies on $\mathrm{LaFe}_{4} \mathrm{P}_{12}$ by Shenoy et al (1982) show that the iron atoms in the compound carry no magnetic moment $\left(<0.01 \mu_{B}\right)$ and are present in a spin-paired $3 d$ configuration. The observed centre shift and area under resonance with temperature could be fitted to a curve with $\theta_{D}=450 \pm 20 \mathrm{~K}$. Assuming a value of $N\left(E_{F}\right)=2$ states/(eV-spin), Shenoy et al (1982) estimated that the electron-phonon coupling is weak $(\lambda=0.4-0.5)$ in this material.

\subsection{Pnictides of the type $A_{2} M_{12} X_{7}$}

Isostructural compounds (about 55 known) of the general formula $\mathbf{A}_{2} \mathbf{M}_{12} \mathrm{X}_{7}$ where $A=$ rare earth $(\mathrm{Ln}), \mathrm{Y}$ or $\mathrm{Zr} ; \mathrm{M}=\mathrm{Fe}, \mathrm{Co}, \mathrm{Ni}$ and $\mathrm{X}=\mathrm{P}$ or As are known (Jeitschko et al 1978). These possess the hexagonal $\mathrm{Zr}_{2} \mathrm{Fe}_{12} \mathrm{P}_{7}$-type structure with $a \sim 9 \AA$ and $c \sim 3.8 \AA$ and have high coordination for all the metal atoms, as is the case for typical intermetallic compounds. The $\mathrm{P}$ atoms are all isolated (and thus no P-P bond exists) and have a nine-fold coordination. The Fe

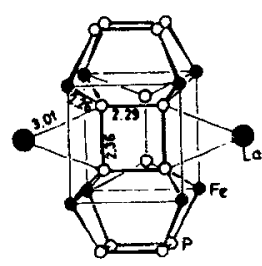

(a)

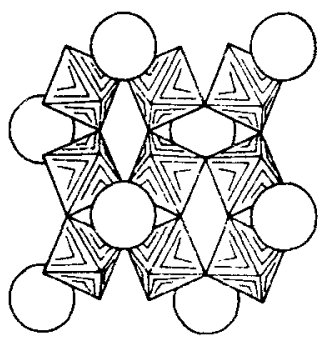

(b)

Figure 17. Crystal structure of $\mathrm{LaFe}_{4} \mathbf{p}_{12}$. (a) Near neighbours of the $P_{4}$ groups in $\mathrm{LaFe}_{4} \mathrm{P}_{12}$. Interatomic distances are in $\mathrm{A}$. (b) One layer of the corner shared $\mathrm{FeP}_{6}$ octahedra is shown with the adjacent La atoms (spheres) above and below. The corners of the octahedra represent the $P$ atoms. The $F e$ atoms inside the octahedra are not shown. 
and $\mathrm{Zr}$ atoms have $12-$ and 18 -fold coordination respectively. The $\mathrm{Fe}-\mathrm{Fe}$ distances are small (2.495 $\AA$ compared to $2.482 \AA$ in iron metal) indicating strong bonding and substantial Fe-P bonding also exists. Jeitschko and coworkers proposed an ionic formulation of the type $\left(\mathrm{Ln}^{3+}\right)_{2}\left(\mathrm{M}^{1.25+}\right)_{12}\left(\mathrm{X}_{7}^{3-}\right)$ and $\mathrm{Zr}_{2}^{4+}\left(\mathrm{M}^{1.08+}\right)_{12}\left(\mathrm{X}^{3-}\right)_{7}$ for the phases where the non-integral oxidation states written for $\mathbf{M}$ only means a delocalization of the electrons on the metals ( $\mathrm{Fe}, \mathrm{Co}$ and $\mathrm{Ni}$ ) rather than mixed valence. Unit cell volume and crystal chemical considerations indicate that an intermediate valency may exist for $\mathrm{Ce}$, Eur and $\mathrm{Yb}$-containing phases.

\subsection{Pnictides of the type $\operatorname{LnM}_{2} X_{2}$}

Rare earth ternary pnictides of the $\mathrm{ThCr}_{2} \mathrm{Si}_{2}$-type $\mathrm{LnM}_{2} \mathrm{X}_{2}(\mathrm{Ln}=$ rare earth or $\mathrm{Th}$; $\mathrm{M}=\mathrm{Fe}, \mathrm{Co}, \mathrm{Ni}$ and $\mathrm{X}=\mathrm{P}, \mathrm{As}$ or $\mathrm{Sb}$ ) have been recently synthesized and characterized (Jeitschko and Jaberg 1980; Ruhl and Jeitschko 1979; Marchand and Jeitschko 1978). Isostructural phosphides $\mathrm{CaM}_{2} \mathrm{P}_{2}(\mathrm{M}=\mathrm{Ni}, \mathrm{Cu}), \mathrm{BaM}_{2} \mathrm{P}_{2}(\mathrm{M}=\mathrm{Zn}$ and $\mathrm{Mn})$ and $\mathrm{BaMn}_{2} \mathrm{As}_{2}$ are also known. The compounds possess a body-centred tetragonal structure $(I 4 / \mathrm{mmm} ; Z=2)$. The $M$ element has a tetrahedral coordination with respect to the $\mathrm{X}$ atom. In the $\mathrm{Ni}$-containing compounds there is a tendency for square planar coordination, although a perfectly square planar $\mathrm{P}$ (or $\mathrm{Si}$ ) coordination of the $\mathrm{Ni}$ atom cannot be achieved in the $\mathrm{ThCr}_{2} \mathrm{Si}_{2}$-type structure. The $\mathrm{A}(\mathrm{Ln})$ atom is surrounded by $8 \mathrm{M}$ and $8 \mathrm{X}$ atoms in the Th-containing compounds, the coordination number reaches 18 instead of 16. Phosphorous atoms exist as pairs $\left(\mathrm{P}_{2}\right)$ whereas in $\mathrm{EuCo}_{2} \mathrm{P}_{2}$, the large $\mathbf{P}-\mathbf{P}$ distance indicates the existence of isolated $\mathrm{P}^{3-}$ ions (Marchand and Jeitschko 1978). Lanthanide contraction is apparent in the unit cell volumes of $\mathrm{LnNi}_{2} \mathrm{P}_{2}$ compounds which also indicates that $\mathrm{Ce}, \mathrm{Eu}$ and $\mathrm{Yb}$ may be present in an intermediate valence state. Intermediate valerce of $\mathrm{Eu}$ in $\mathrm{EuNi}_{2} \mathrm{Pi}_{2}$ has been verified recently by Nagarajan et al $(1981,1983)$ and Sampathkumaran et al 1982). Mixed valence of Eu may also be a feature in the arsenide and antimonide phases. As expected, the unit cell volume increases on going from $P$ to $A s$ to $S b$ for a given $\operatorname{LnM}_{2} X_{2}$-system. Based on the interatomic distance and unit cell volumes of the $\mathrm{Co}$ and $\mathrm{Ni}$-containing phosphides, Jeitschko proposed an ionic formulation of the type $\left.\mathrm{Eu}^{2+}\left(\mathrm{Co}^{2+} \mathrm{Co}^{2+}\right) \mathrm{P}^{3-} \mathrm{P}^{3-}\right)$ and $\mathrm{Eu}^{2+}\left(\mathrm{Ni}^{1+} \mathrm{Ni}^{1+}\right)\left(\mathrm{P}_{2}\right)^{4-}$ where the $\mathrm{M}$ element is present in a low oxidation state.

Detailed physical property studies of the pnictide phases with the $\mathrm{Zr}_{2} \mathrm{Fe}_{12} \mathrm{P}_{7}$ - and $\mathrm{ThCr}_{2} \mathrm{Si}_{2}$-type structures are yet to be made. In view of the fact that metallic behaviour and superconductivity have been discovered in the related ternary phosphides $\mathrm{LaM}_{4} \mathrm{P}_{12}(\mathrm{M}=\mathrm{Fe}, \mathrm{Ru})$, it is possible that superconductivity may be exhibited by these metal excess ternary system of compounds as well.

\section{Ternary oxides}

Ternary oxides with the perovskite $\left(\mathrm{ABO}_{3}\right.$-type $)$ and spinel $\left(\mathrm{AB}_{2} \mathrm{O}_{4}\right.$-type $)$ structure are known to be not very conducive to high $T_{c}$ superconductivity (Nb-doped or reduced $\mathrm{SrTiO}_{3}$ has a $T_{c} \leqslant 1 \mathrm{~K}$; copper containing chalcogenide spinels, $\mathrm{CuRh}_{2} \mathrm{X}_{4}$ $\mathrm{X}=\mathrm{S}$, Se, have $T_{\mathrm{c}} \leqslant 5 \mathrm{~K}$ ). However, one isolated example in each of the above structure type is now known with $T_{\mathrm{c}} \sim 11-13.5 \mathrm{~K}$ : (i) $\mathrm{BaPb}_{1-x} \mathrm{Bi}_{x} \mathrm{O}_{3}(x=0.05-0.3)$ and (ii) $\mathrm{Li}_{1+x} \mathrm{Ti}_{2-x} \mathrm{O}_{4}(x=0 \cdot 1-0 \cdot 3)$. The compounds are type II superconductors.

Sleight et al (1975) discovered that the orthorhombic $\mathrm{BaPbO}_{3}$ and monoclinic $\mathrm{BaBiO}_{3}$ perovskites form complete series of solid solutions and superconductivity is 
induced for $x=0.05-0.30$ in $\mathrm{BaPb}_{1-x} \mathrm{Bi}_{x} \mathrm{O}_{3}$ whereas the end members $(x=0$ and 1$)$ are metallic and semiconducting respectively. Later studies by Khan et al (1977), Gilbert et al (1978, 1982) and Suzuki et al (1980) confirmed the above observations on samples in the bulk and thin-film form. Studies also showed that $T_{c}$ increases from about $9 \mathrm{~K}$ for $x=0.05$ to a maximum of about $13 \mathrm{~K}$ at $x=0.3$. For $x \geqslant 0.35$, the superconductivity is destroyed and in fact the phases are semiconducting in nature. It is significant to note that $T_{c}$ is maximum for that value of $x$ which is slightly below the value where the metal-to-semiconductor transition sets in. One feature of this perovskite system is that the superconducting transitions are broad $(1-2 \mathrm{~K}$ width) as measured by the Meisner effect. Initial experiments on alkali metal doping (at the Basite) indicated an improvement in the sharpness of the transition width without affecting the $T_{c}$ value for a given value of $x$. Later experiments showed that a slight excess of $\mathrm{Pb}$ (over the nominal $x$ ) also produces the same effect showing thereby that the broad transition may be related to non-random distribution of $\mathrm{Pb}$ and $\mathrm{Bi}$ at site of the perovskite structure.

Since there are no $d$ electrons in $\mathrm{BaPb}_{1-} \mathrm{Bi}_{x} \mathrm{O}_{3}$, the conduction band consists overlapping $\mathrm{Pb}$ 6s and $\mathrm{O} 2 p$ bands. Sleight et al (1975) proposed a schematic energy level diagram to explain the observed properties.

$\mathrm{Li}_{1+x} \mathrm{Ti}_{2-x} \mathrm{O}_{4}(0.1<x \leqslant 0.3)$ was first synthesized by Johnston et al (1973) and found to be superconducting with a high $T_{c}$ ranging from $10-12 \mathrm{~K}$. The homogeneity range for the spinel structure varies from $x=0.33(a=8.36 \AA)$ to approximately $x=-0.2(a=8.4 \AA)$. The superconducting compositions are in the vicinity of the metal-to-semiconductor transition since for $x \sim 0-0.1$, the samples are metallic and those with $x \approx 0.15-0.33$ are semiconductors. Maximum $T_{c}$ is found for $x=0$ and drops abruptly for $x \approx 0.05-0.1$ to a value less than $1.5 \mathrm{~K}$. Magnetic susceptibility (Johnston 1976; Murphy et al 1982), heat capacity (McCallum et al 1976) and critical field measurements (Roy et al 1977; Foner and McNiff 1976) confirm that superconductivity is a bulk property of the $\mathrm{LiTi}_{2} \mathrm{O}_{4}$ compound and the $\mathrm{Ti} 3 d$ electrons are responsible for the observed behaviour.

\section{Ternary chalcogenides}

\subsection{Ternary molybdenum chalcogenides (Chevrel phases)}

The ternary molybdenum chalcogenides $\mathrm{A}_{x} \mathrm{Mo}_{6} \mathrm{Ch}_{8}(A=$ metal; $x=0-4 ; \mathrm{Ch}=\mathrm{S}, \mathrm{Se}$, Te) represent a family of isostructural METs compounds with remarkable chemical and physical properties. Many of them are high $T_{c}(\leqslant 15 \mathrm{~K})$ and high critical magnetic field $\left(H_{\mathrm{c} 2} \sim 600 \mathrm{kOe}\right)$ superconductors. Originally discovered in 1971, they have been extensively investigated in recent years. The structure and chemistry of these phases are well understood to a certain extent but a complete understanding of the physical properties including superconductivity, exciting new possibilities and phase equilibrium relationships need a lot more future research. Excellent reviews are available in the literature and hence only a brief account will be presented here (Fischer 1978; Yvon 1979; Schöllhorn 1980, 1983a, b; Umarji 1980; Shenoy et al 1981; Subba Rao and Shenoy 1981; Corbett 1981; Maple and Fischer 1982; Fischer and Maple 1982; Chevrel and Sergent 1982; Pobell et al 1982; Simon 1981; Poppe 1980).

9.1a Structure and stoichiometry: The compounds, $\mathrm{A}_{\mathbf{x}} \mathrm{Mo}_{6} \mathrm{Ch}_{8}$, possess a hexagonal- 
rhombohedral crystal structure $\left(a \sim 6.5 \AA ; \alpha \sim 90^{\circ}\right)$. The structure essentially consists of a rhombohedral stacking of $\mathrm{Mo}_{6} \mathrm{Ch}_{8}$ units in such a way that the A atoms occupy the empty channels. Each $\mathrm{Mo}_{6} \mathrm{Ch}_{8}$ unit consists of an octahedral cluster of Mo atoms enclosed in a slightly deformed cube of $\mathrm{Ch}$ atoms (figure 18). The intracluster and intercluster Mo-Mo distances are small (intra, 2.7 $\AA$, same as that in Mo-metal: inter $3.2 \AA$ ) with the result that strong metal-metal bonding exists within the cluster and sufficiently strong interactions exist between intercluster Mo-Mo atoms. The A atoms are mostly the electropositive elements of the periodic table (figure 19). The stoichiometry $x$ in $\mathrm{A}_{x} \mathrm{Mo}_{6} \mathrm{Ch}_{8}$ and the site occupancy depends on the ionic radius of the A metal. Small ionic radii elements (e.g., $\mathrm{Cu}, \mathrm{Ni}, \mathrm{Co}$ etc) occupy the so-called off-channel positions (with essentially tetrahedral coordination of $\mathrm{Ch}$ atoms) and $x$ can vary from $0-4$. On the other hand, large ionic radii elements (e.g., $\mathrm{Pb}, \mathrm{Sn}, \mathrm{La}, \mathrm{Eu}, \mathrm{Yb}$ ) occupy the central channel positions (figure 18; essentially 8-fold coordination) and $x$ is fixed and

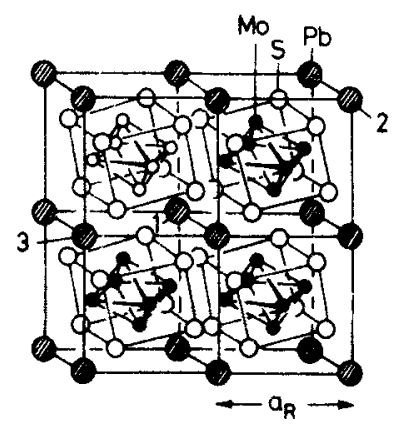

Figure 18. Structure of $\mathrm{PbMo}_{6} \mathrm{~S}_{8} . \mathrm{Mo}_{6} \mathrm{~S}_{8}$ unit is turned by $\sim 27^{\circ}$ with respect to rhombohedral cell vectors. $\mathrm{Pb}$ occupies the channel position.
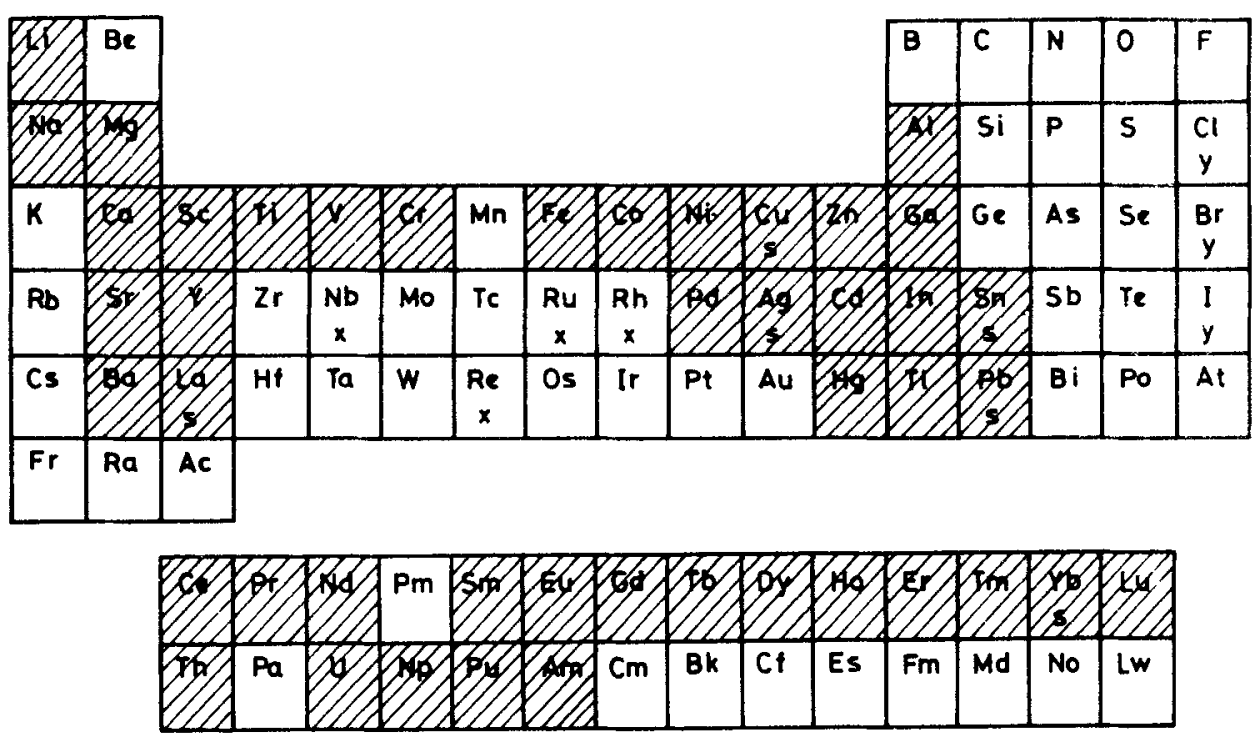

Figure 19. Partial periodic table showing the A elements (shaded) which form the $\mathrm{A}_{x} \mathrm{Mo}_{6} \mathrm{Ch}_{8}\left(\mathrm{Ch}=\mathrm{S}\right.$, Se) phases. $s$ indicates the phases which have $T_{c}$ between 8-15 K. Symbols $x$ and $y$ indicate that partial substitution is possible with these elements at the Mo and Ch site respectively (After Fischer 1978 with some modification). 
close to 1. The $\mathrm{A}$ atoms effect an electronic charge transfer to the $\mathrm{Mo}_{6} \mathrm{Ch}_{8}$ unit (in essence, to the Mo-4d conduction band) (Fischer 1978; Ramasamy et al 1981; Yashonath et al 1981; Freeman and Jarlborg 1982). Chevrel phases are amenable to chemical substitution at the $A, M o$ and $C h$ sites. In addition to the $\left(\mathrm{A}_{1-x} \mathrm{~A}_{x}^{\prime}\right) \mathrm{Mo}_{6} \mathrm{Ch}_{8}$-type solid solutions, isostructural phases $\left(\mathrm{Mo}_{2} \mathrm{Re}_{4}\right) \mathrm{Se}_{8}$, $\left(\mathrm{Mo}_{4} \mathrm{Ru}_{2}\right) \mathrm{Se}_{8}, \quad\left(\mathrm{Mo}_{6-x} \mathrm{M}_{x}\right) \mathrm{Se}_{8}, \quad(\mathrm{M}=\mathrm{Nb}, \quad \mathrm{Rh}), \quad \mathrm{Mo}_{6} \mathrm{Ch}_{6} \mathrm{X}_{2} \quad(\mathrm{X}=\mathrm{Cl}, \mathrm{Br}, \mathrm{I})$, $\mathrm{Cu}_{x} \mathrm{Mo}_{6} \mathrm{~S}_{6} \mathrm{I}_{2}$ and $\mathrm{Li}_{2} \mathrm{Mo}_{6} \mathrm{~S}_{6} \mathrm{Br}_{2}$ have been isolated and studied (Fischer 1978; Radhakrishnan et al 1981; Umarji et al 1981a, b; Sankaranarayanan et al 1982; Perrin et al 1980; Behlok and Robinson 1983; Alekseevskii et al 1978, 1982). Interestingly enough, and true to the nature of the channel structure, the $A$ atoms, when small (e.g. $\mathrm{Li}$, $\mathrm{Cu}, \mathrm{Co}, \mathrm{Ni}$ ), can be leached out by a simple mineral acid treatment or electrochemical oxidation to give rise to the binary $\mathrm{Mo}_{6} \mathrm{Ch}_{8}$ compounds. Of course, the reverse process of insertion of foreign metal atoms into the channels of $\mathrm{Mo}_{6} \mathrm{Ch}_{8}$ to give ternaries is also possible and has been studied (Fischer 1978; Schöllhorn 1980; Umarji et al 1980).

9.1b Superconductivity and related properties: The binary $\mathrm{Mo}_{6} \mathrm{Ch}_{8}$ and many ternaries, $\mathrm{A}_{\mathbf{x}} \mathrm{Mo}_{6} \mathrm{Ch}_{8}$ exhibit metallic behaviour, but with fairly high resistivity $\left(\rho \sim 10^{-3} \mathrm{ohm} \mathrm{cm}\right)$. For $\mathrm{A}=$ alkali metal, post transition metal or rare earths, the ternaries exhibit superconductivity. $T_{c}$ values between $8-15 \mathrm{~K}$ are encountered for $\mathrm{A}=\mathrm{Pb}, \mathrm{Sn}, \mathrm{Cu}, \mathrm{Ag}, \mathrm{La}$ and $\mathrm{Yb}$. Binary $\mathrm{Mo}_{6} \mathrm{Se}_{8}$ has a $T_{c}$ of $6.3 \mathrm{~K}$ whereas $\mathrm{Mo}_{6} \mathrm{~S}_{8}$ is superconducting below $1 \mathrm{~K}$ and $\mathrm{Mo}_{6} \mathrm{Te}_{8}$ does not become superconducting up to the lowest temperatures. $\mathrm{Mo}_{6} \mathrm{~S}_{6} \mathrm{X}_{2}(\mathrm{X}=\mathrm{Br}$ and $\mathrm{I})$ exhibit a $T_{c}$ of $13-14 \mathrm{~K}$. Magnetic susceptibility, heat capacity data and theoretical band structure calculations show that there exists a large density of states at the Fermi level in $\mathrm{A}_{x} \mathrm{Mo}_{6} \mathrm{Ch}_{8}$ and the metallic and superconducting behaviour are exclusively due to the Mo-4d electrons (Fischer 1978; Freeman and Jarlborg 1982; Andersen et al 1982). The number of electrons per $\mathrm{Mo}_{6}$ cluster (NEC) is an important parameter in determining the properties because it determines the occupancy of the $4 d$-conduction bands. For $\mathrm{Mo}_{6} \mathrm{~S}_{8}$, NEC is 20 $((6 \times 6)-(2 \times 8)$ and it becomes 21,22 or 23 depending on the valency of A metal in $\mathrm{AMo}_{6} \mathrm{~S}_{8}(\mathrm{Ag}, 20+1 ; \mathrm{Pb}, 20+2 ; \mathrm{La}, 20+3$ etc) but the $4 d$-conduction band is still partially filled in these cases. Metallic and superconducting behaviour can thus be explained. Band structure calculation and also simple chemical bonding arguments predict that the $4 d$-subband will be completely filled for an NEC of 24 (assuming Mo-Mo intracluster bonding, 12 edges in the $\mathrm{Mo}_{6}$-octa cluster require $12 \times 2=24$ electrons to form electron-pair bonds) and the material should exhibit semiconductor behaviour (because the upper lying Mo-4d subband is separated by an energy of 1-1.5 eV). Indeed, the compounds $\mathrm{Mo}_{2} \mathrm{Re}_{4} \mathrm{~S}_{8}, \mathrm{Mo}_{2} \mathrm{Re}_{4} \mathrm{Se}_{8}, \mathrm{Mo}_{4} \mathrm{Ru}_{2} \mathrm{Se}_{8}$ and $\mathrm{Cu}_{4}^{1+} \mathrm{Mo}_{6} \mathrm{~S}_{8}$ which possess an NEC of 24 are found to exhibit a semiconductor behaviour.

According to the McMillan-Allen-Dynes formalism of the original BCs theory on the origin of superconductivity in a metal, $T_{c}$ is directly dependent on the density of electronic states at the Fermi level, the electron-phonon interaction and phonon density of states, the latter being proportional to the Debye temperature. Measurements till todate show that the Chevrel phases satisfy all the criteria and no exotic mechanisms other than the phonon (BCS) mechanism need be invoked to explain the superconductivity. However, in the rare earth containing Chevrel phases, $\mathrm{LnMo}_{6} \mathrm{~S}_{8}$, which order antiferromagnetiçally at low temperatures, the superconducting state seems to be modified to a non-BCs type due to a possible change in pairing (Ishikawa et al 1982). No 
universal correlation between $T_{c}$ and known structural, chemical or physical parameters seems to exist in the Chevrel phases examined so far. A somewhat rough correlation may exist between $T_{c}$ and hexagonal lattice parameter ratio $(c / a)$ in a related series of compounds but efforts to raise $T_{c}$ beyond $15 \mathrm{~K}$ have not been successful. A detailed explanation for the existence of very large critical fields in Chevrel phases has been provided recently by Decroux and Fischer (1982).

9.1c. Coexistence of superconductivity and magnetic order and the reentrant behaviour: Rare earth Chevrel phases, $\mathrm{LnMo}_{6} \mathrm{Ch}_{8}(\mathrm{Ch}=\mathrm{S}, \mathrm{Se} ; \mathrm{Ln}=$ rare earth or $\mathrm{Y})$, exhibit superconductivity (except for $\mathrm{Ln}=\mathrm{Ce}, \mathrm{Eu}$ ) despite the fact that they contain $\sim 7$ atom \% paramagnetic ions (e.g., $\mathrm{Ln}=\mathrm{Tb}, \mathrm{Dy}, \mathrm{Ho}, \mathrm{Er}$ ). This indicates that the interaction of the $f$-electron spins with the Mo- $4 d$ conduction electrons is not much. Magnetic susceptibility and other studies have shown that the rare earth is present as $\mathrm{Ln}^{3+}$ ion in $\mathrm{LnMo}_{6} \mathrm{Ch}_{8}$ phases (except Eu and $\mathrm{Yb}$ which are present in $2+$ state) and since many of these support a large magnetic moment, there exists the possibility of long range magnetic order developing at low temperatures and still retain the superconducting behaviour. Detailed studies by a variety of techniques including neutron diffraction have indeed shown that antiferromagnetism (with Néel temp., $T_{N}$ ) and superconductivity (with transition temp.,$T_{c}$ ) in many of the Ln-Chevrel phases coexist with $T_{N}<T_{c}$ (table 3). The compound $\mathrm{HoMo}_{6} \mathrm{~S}_{8}$ exhibits the interesting reentrant behaviour similar to $\mathrm{ErRh}_{\mathbf{4}} \mathrm{B}_{\mathbf{4}}$ and other ternary systems (table 4). Neutron diffraction studies (Lynn 1983; Lynn et al 1981; 1983b) have shown that a sinusoidally modulated magnetized state (with a period of $250 \mathrm{~A}$ ) coexists with superconductivity just above $T_{c 2}$ in $\mathrm{HoMo}_{6} \mathrm{~S}_{8}$ analogous to the case of $\mathrm{ErRh}_{4} \mathrm{~B}_{4}$. Coexistence of superconductivity and ferromagnetism has been realized by Ishikawa et al (1982) in the pseudoternary system $\mathrm{Ho}_{1-x} \mathrm{Eu}_{x} \mathrm{Mo}_{6} \mathrm{~S}_{8}$ (see table 4). Reentrant behaviour can be induced in $\mathrm{DyMo}_{6} \mathrm{~S}_{8}$ and $\mathrm{GdMo}_{6} \mathrm{~S}_{8}$ to some extent by the application of magnetic field, similar to the case of $\mathrm{LnRh}_{4} \mathrm{~B}_{4}$ antiferromagnetic superconductors.

\subsection{Condensed molybdenum cluster phases}

Ternary molybdenum compounds containing $\left(\mathrm{Mo}_{9} \mathrm{Ch}_{11}\right),\left(\mathrm{Mo}_{12} \mathrm{Ch}_{14}\right)$ or $\left(\mathrm{Mo}_{6 / 2} \mathrm{Ch}_{6 / 2}\right)(\mathrm{Ch}=\mathrm{S}$, Se, Te) units resulting from a linear condensation of the octahedral $\mathrm{Mo}_{6}$ clusters have been recently synthesized and studied. Representative compounds are: $\mathrm{Ag}_{x} \mathrm{Mo}_{9} \mathrm{Se}_{11}(x \approx 4)$ (Gougeon et al 1983), $\mathrm{A}_{2} \mathrm{Mo}_{9} \mathrm{~S}_{11}(\mathrm{~A}=\mathrm{K}, \mathrm{Tl})$, $\mathrm{K}_{2} \mathrm{Mo}_{15} \mathrm{~S}_{19}, \mathrm{~A}_{2} \mathrm{Mo}_{15} \mathrm{Se}_{19}(\mathrm{~A}=\mathrm{K}, \mathrm{Ba}, \mathrm{Tl}), \mathrm{In}_{x} \mathrm{Mo}_{15} \mathrm{Se}_{19}(x=2 \cdot 9-3 \cdot 4)$ (Chevrel et al 1981; Chevrel and Sergent 1982), $\mathrm{AMo}_{3} \mathrm{~S}_{3}(\mathrm{~A}=\mathrm{K}, \mathrm{Rb}, \mathrm{Cs})$ (Huster et al 1983) and $\mathrm{AMo}_{3} \mathrm{Ch}_{3}(\mathrm{~A}=\mathrm{In}, \mathrm{Tl} ; \mathrm{Ch}=\mathrm{Se}, \mathrm{Te})$ (Hönle et al 1980). The compounds crystallize with a hexagonal symmetry. The $a$ lattice parameter is $\sim 9 \AA$ but the $c$ parameter varies with the $\mathrm{Mo}_{x} \mathrm{Ch}_{y}$ content and decreases to a low value $(\sim 4.5 \AA)$ for $x: y=3: 3$. The structure of the $\mathrm{A}_{x} \mathrm{Mo}_{15} \mathrm{Se}_{19}$ phases is characterized by the presence of $\mathrm{Mo}_{6} \mathrm{Se}_{8}$ and $\mathrm{Mo}_{9} \mathrm{Se}_{11}$ units, the latter resulting from a fusion of two $\mathrm{Mo}_{6}$ octahedra along a common face, but all the Mo atoms have the same chalcogen environment as existing in the Chevrel phases. The intracluster distance is small ( $\sim 2.7 \AA$ as in Chevrel phases) but intercluster distance is large ( 3.4-3.5 $\mathrm{A}$ ). The indium and other $\mathrm{A}$ atoms are situated in a three-dimensional network of channels similar to the $\mathrm{A}_{x} \mathrm{Mo}_{6} \mathrm{Ch}_{8}$ compounds (see $\S 9 \cdot 1)$. All the phases examined so far are metallic and superconducting but $T_{c}$ values are 
low $(\leqslant 4 \cdot 3 \mathrm{~K})$. The $\mathrm{In}_{2.9} \mathrm{Mo}_{15} \mathrm{Se}_{19}$ phase has been found to possess a relatively high value of $H_{c 2}$ of $210 \mathrm{kOe}$.

\section{Summary and conclusions}

Metal excess ternary system (METs) of compounds are usually stoichiometric, but also can be nonstoichiometric compounds (one of which is a nonmetal) occupy a distinct set or sets of crystallographic lattice sites and only a part of the valence electrons of the metals are involved in chemical bonding with nonmetallic atom. The excess electrons are delocalized and whenever there is a strong metal-metal bonding (metallic bond), the compound exhibits a metallic behaviour. This is a necessary condition for the exhibition of superconductivity by any METS compound. Only a few of the large number of known MErs have been examined in detail till to-date. However, it is clear that certain specific crystal structures and a specific type of bonding between the atoms in METs are favourable for high $T_{c}$ superconductivity. In fact Matthias and others have pointed out earlier that the high $T_{c}$ exhibited by the $\mathrm{LnRh}_{4} \mathrm{~B}_{4}$ and $\mathrm{A}_{x} \mathrm{Mo}_{6} \mathrm{Ch}_{8}$ phases is due to the presence of $\mathrm{Rh}$ and Mo clusters respectively. Similarly, the carbon atoms when located inside an octahedra of metal atoms in the METs carbides give rise to high $T_{c}$ superconductivity. However, from the preceding sections we note that high $T_{c}$ is not obtained whenever there is an inter-penetration -of different types of clusters or condensation of metal atom clusters within the structure. Hence, the presence of isolated metal atom and/or non metal atom clusters is favourable to high $T_{c}$ superconductivity. Also, high crystal symmetry (cubic, rhombo or tetra) of the structure appears to favour high $T_{c}$ compared to the less symmetric structures in METS compounds. The two isolated examples of the oxide systems show that electronic (and perhaps also the crystal structure) instability induced by the compositional variation is a factor which governs the high $T_{c}$ behaviour. Presumably this line of approach extended to the METs may yield fruitful results in the search for new high $T_{c}$ materials. Finally, we note that from the limited studies conducted on Co and Fe-containing stannides and phosphides, the $3 d$ transition metals need not be counted out of the possible METs in the search for high temperature superconductivity.

\section{Acknowledgements}

Thanks are due to the Department of Science and Technology, Government of India, New Delhi for the award of a research grant.

\section{References}

Adrian H, Müller R, Behrle R, Saemann-Ischenko G and Voit G 1981 Physica B108 1281

Alexkeevskii N E, Mitin A V, Bazan C, Dobrovolskii N M and Ronczka B 1978 Sov. Phys.-JETP 74384

Alexkeevskii N E, Mitin A V, Bazan C, Gren B and Folcik L 1982 Solid State Commun. 41569

Andersen O K, Klose W and Nohl H 1982a in Superconductivity in ternary compounds I (eds) $\Phi$ Fischer and M B Maple (New York: Springer Veriag), Vol. 32

Andres K, Remeika J P, Espinosa G P and Cooper A S 1981 Phys. Rev. B23 1179

Ballestraci R 1976 C.R. (Paris) 282291

Barz H 1980 Mater. Res. Bull. 151489

Barz H, Ku H C, Meisner G P, Fisk Z and Matthias B T 1980 Proc. Natl. Acad. Sci. USA 773132

Behlok R J and Robinson W R 1983 Mater. Res. Bull. 181069 
Braun D J and Jeitschko W 1980a J. Solid State Chem. 32357

Braun D J and Jeitschko W 1980b J. Less Common Metals 72147

Braun D J and Jeitschko W 1980c J. Less Common Metals 7633

Braun H F 1981 in Ternary superconductors (eds) G K Shenoy, B D Dunlap and F Y Fradin (New York Elsevier: North Holland) p. 225

Braun H F and Segre C U 1980 Solid State Commun. 35735

Braun H F and Segre C U 1981 in Ternary superconductors (eds) G K Shenoy et al (New York: Elsevier North Holland), p. 239

Braun H F, Segre C U, Acker F, Rosenberg M, Dey S and Deppe P 1981 J. Magn. Mag. Mater. 25117

Braun H F, Yvon K and Braun R M 1980 Acta. Crystallogr. B36 2397

Bulaevski L N, Rusinov A I and Kulic M 1979 Solid State Commun. 3059

Cashion J D, Shenoy G K, Niarchos D, Viccaro P J and Falco C M 1980 Phys. Lett. A79 454

Cashion J D, Shenoy G K, Niarchos D, Viccaro P J, Aldred A T and Falco C M 1981 J. Appl. Phys. 522180

Chenavas J, Hodeau J L, Collomb A, Marezio M. Remeika J P and Vandenberg J M 1981 in Ternary Superconductors (eds) G K Shenoy, B D Dunlap and F Y Fradin (New York: Elsevier North Holland), p. 219

Chevalier B, Cole A, Lejay P and Etourneau J 1981 Mater. Res. Bull. 161067

Chevalier B, Cole A, Lejay P, Vlasse M, Etourneau J. Hagenmuller P and Georges R 1982a Mater. Res. Buli. 17251

Chevalier B, Lejay P, Cole A, Vlasse M and Etourneau J 1982b Solid State Commun. 41801

Chevalier B, Lejay P, Etourneau J and Hagenmuller P 1983 Mater. Res. Bull. 18315

Chevalier B. Lejay P, Etourneau J, Vlasse M and Hagenmuller P 1982e Mater. Res. Bull. 171211

Chevalier B, Lejay P, Etourneau J, Vlasse M and Hagenmuller P 1982d Proc. VII Intl. Conf. Solid Compds. Transition Elem., Grenoble. France

Chevalier B, Lejay P, Vlasse M, Etourneau J and Hagenmuller P 1982c Proc. II Intl. Conf. on Solid State Chemistry, Netherlands

Chevrel R, Sergent M and Prigent J 1971 J. Solid State Chem. 3515

Chevrel R, Potel M and Sergent M 1981 in Ternary superconductors (eds) G K Shenoy B D Dunlap and F Y Fradin (New York: Elsevier, North Holland) p. 7

Chevrel R and Sergent M 1982 in Superconductivity in ternary compounds I (eds) $\Phi$ Fischer and M B Maple (New York: Springer Verlag) p. 25

Cooper A S 1980 Mater. Res. Bull. 15799

Corbett J D 1981 J. Solid State Chem. 3956

Decroux M and Fischer $\Phi 1982$ in Superconductivity in ternary compounds II (eds) M B Maple and $\Phi$ Fischer (New York: Springer Verlag)

Dhar S K, Malik S K, Vijayaraghavan R and Wallace W E 1983 J. Less Common Metals 94266

Donohue P C and Bierstedt P E 1969 Inorg. Chem. 82690

Espinosa G P 1980 Mater. Res. Bull. 15791

Espinosa G P, Cooper A S, Barz H and Remeika J P 1980 Mater. Res. Bull. 151635

Espinosa G P, Cooper A S and Barz H 1982 Mater. Res. Bull. 17963

Felner I and Nowik I 1983 Solid State Commun. 47831

Ferrel R A, Bhattacharjee J K and Bagchi A 1979 Phys. Rev. Lett, 43154

Fischer Ф 1978 Appl. Phys. 161

Fischer $\Phi$ and Maple M B 1982 (eds) Superconductivity in ternary compounds I (New York: Springer Verlag)

Fisk Z, Lambert S E, Maple M B, Remeika J P, Espinosa G P, Cooper A S, Barz H and Oseroff S 1982 Solid State Commun. 4163

Foner S and McNiff Jt E J 1976 Solid State Commun. 20995

Freeman A J and Jarlborg T 1982 in Superconductivity in ternary compounds $I I$ (eds) M B Maple and $\Phi$ Fischer (New York: Springer Verlag)

Gilbert L R, Messier R and Roy R 1978 Thin Solid Films 54 129; 1982 Mater. Res. Bull. 17467

Gougeon P, Potel M, Padiou J and Sergent M 1983 Compt. Rend (Paris) 296351

Greenside H S, Blount E I and Varma C M 1981 Phys. Ret. Lett. 4649

Grüttner A and Yvon K 1979 Acta Crystallogr. B35 451

Hamaker H C, Woolf L D, Mackay H B, Fisk Z and Maple M B 1979 Solid State Commun. 32289

-Hamaker H C and Maple M B 1981 in Ternary superconductors (eds) G K Shenoy, B D Dunlap and F Y Fradin (New York: Elsevier North Holland) p. 201

Hamaker H C, Ku H C and Maple M B 1982 Solid Stat' Commun. 43455 
Hodeau J L, Chenavas J, Marezio M and Remeika J P 1980 Solid State Commun. 36839

Hönle W, Von Shnering H G, Lipka A and Yvon K 1980 J. Less Common Metals 71135

Hovestreydt E, Engel N, Klepp K, Chebot B and Parthe E 1982 J. Less Common Metals 85247

Hull G W, Wernick J H, Geballe T H, Waszczak J V and Bernardini J E 1981 Phys. Rev. B24 6715

Hulliger F 1981 in Structure and bonding in crystals (New York: Academic Press) Vol. II

Huster J, Schippers G and Bronger W 1983 J. Less Common Metals 91333

Ishikawa M, Sergent M and Fischer $\Phi 1981$ Phys. Lett. $\mathbf{A 8 2} 30$

Ishikawa M, Fischer O and Muller J 1982 in Superconductivity in ternary compounds II (eds) M B Maple and

O Fischer (New York: Springer Verlag)

Jacobson R A 1983 J. Less Common Metals 92177

Jaric M V 1979 Phys. Rev. B20 4486

Jaric M V 1980 Phys. Rev. B22 463

Jeitschko W and Braun D 1977 Acta Crystallogr. B33 3401

Jeitschko W, Braun D J, Ashcraft R H and Marchand R 1978 J. Solid State Chem. 25309

Jeitschko W and Jaberg B 1980 J. Solid State Chem. 35312

Jeitschko W, Nowotny H and Benesovsky F 1963 Monatsch. Chem. 94 247, 332

Johnson V and Jeitschko W 1972 J. Solid State Chem. 4123

Johnston D C 1976 J. Low Temp. Phys. 25145

Johnston D C 1977 Solid State Commun. 24699

Johnston D C 1981 Physica B108 755

Johnston D C 1982 Solid State Commun. 42453

Johnston D C and Braun H F 1982 in Superconductivity in ternary compounds II (eds) M B Maple and $\Phi$ Fischer (New York: Springer Verlag) p. 11

Johnston D C, Prakash H, Zachariasen W H and Viswanathan R 1973 Mater. Res. Bull. 8777

Johnston J, Toth L, Kennedy K and Parker E R 1964 Solid State Commun. 2123

Khan Y, Nahm K, Rosenberg M and Willner H 1977 Phys. Status Solidi 3979

Klepp K and Parthe E 1982 Acta Crystallogr. B38 1541

Ku H C 1980 Ph.D. Diss., Univ. Calif. San Diego USA

Ku H C and Acker F 1980 Solid State Commun. 35937

Ku H C, Acker F and Matthias B T 1980 Phys. Lett. A76 399

Ku H C, Johnston D C, Matthias B T, Barz H, Burri G and Rinderer L 1979 Mater. Res. Bull. 141591

Ku H C, Meisner G P, Acker F and Johnston D C 1980 Solid State Commun. 3591

Ku H C and Meisner G P 1981 J. Less Common Metals 7899

Ku H C and Shelton R N 1980 Mater. Res. Bull. 15441

Ku H C and Shelton R N 1981 Solid State Commun. $\mathbf{4 0} 237$

Kumagai K, Inoue Y, Kohori Y and Asayama K 1981 in Ternary superconductors (eds) G K Shenoy, B D Dunlap and F Y Fradin (New York: Elsevier, North Holland), p. 185

Kuz'ma, Yu B and Bilonizhko N S 1972 Sov. Phys. Crystallogr. 16897

Kuz'ma, Yu B, Kripyakevich P I and Bilonizhko N S 1969 Dopavidi. Akad. Nauk. Ukr. RSR Ser. A(10) 939

Kuz'ma, Yu B, Bilonizhko N S, Mykhalenko S L, Stepanchikova G F and Chaban N F 1979 J. Less. Common Metals 6751

Lambert S E, Fisk Z, Hamaker H C, Maple M B, Woolf L D, Remeika J P and Espinosa G P 1981 in Ternary superconductors (eds) G K Shenoy, B D Dunlap and F Y Fradin (New York: Elsevier, North Holland), p. 247

Lander G H, Sinha S K and Fradin F Y 1979 J. Appl. Phys. 501990

Lejay P, Chevalier B, Etourneau J, Hagenmuller P and Peshev P 1981a Synth. Metals 4139

Lejay P, Chevalier B, Etourneau J and Hagenmuller P 1981b J. Less Common Metals 82193

Lynn J W, Shirane G, Thomlinson W and Shelton R N 1981 Phys. Rev. Lett. 46368

Lynn J W 1983 J_Less Common Metals 9475

Lynn J W, Pynn R, Joffrin J, Ragazzoni J L and Shelton R N 1983a Phys. Rev. B27 581

Lynn J W, Shelton R N, Horng H E and Glinka C J 1983b (to be published)

Machida K and Matsubara T 1979 Solid State Commun. 31791

Mackay H B, Woolf L D, Maple M B and Johnston D C 1980 J. Low Temp. Phys. 41639

Mahanti S D, Sinha K P and Atre M V 1981 J. Low Temp. Phys. 441

Malik S K, Dhar S K, Vijayaraghavan R and Wallace W E 1982 J. Appl. Phys. 538074

Maple M B 1976 Appl. Phys. 9179

Maple M B and Fischer $\Phi 1982$ Magnetic superconductors in Superconductivity in ternary compounds II 
Topics in Current Phys. (eds) M B Maple and O Fischer (New York: Springer Verlag) 34

Maple M B, Hamaker H C and Woolf L D 1982 in Superconductivity in ternary compounds II (eds) $M$ B Maple and $\Phi$ Fischer (New York: Springer Verlag)

Marchand R and Jeitschko W 1978 J. Solid State Chem. 24351

Matsumoto H, Umezawa H and Tachiki M 1979 Solid State Commun. 31157

Matthias B T, Geballe T H and Compton V B 1963 Rev. Mod. Phys. 351

Matthias B T, Corenzwit E, Vandenberg J M and Barz H 1977 Proc. Natl. Acad. Sci. (USA) 741334

Matthias B T, Marezio M, Corenzwit E, Cooper A S and Barz H 1972 Science (USA) 1751465

McCallum R W, Johnston D C, Luengo C A and Maple M B 1976 J. Low Temp. Phys. 25177

Meisner G P 1981 Physica B108 763

Meisner G P, Ku H C and Barz H 1983 Mater. Res. Bull. 18983

Moncton D E, McWhan D B, Eckert J, Shirane G and Thomlinson W 1977 Phys. Ret. Lett. 391164

Moncton D E, McWhan D B, Schmidt P H, Shirane G, Thomlinson W, Maple M B, Mackay H B, Woolf L D, Fisk Z and Johnston D C 1980 Phys. Rev. Lett. 452060

Müller R, Shelton R N, Richardson Jr J W and Jacobson R A 1983 J. Less Common Metals 92177

Murphy D W, Greenblatt M, Zahurak S M, Cava R J, Waszezak J V, Hull Jr G W and Hutton R S 1983 Rei. de. Chim. Miner. 19441

Nagarajan R, Sampathkumaran E V, Gupta L C, Vijayaraghavan R, Prabhawalkar V. Bhaktdarshan and Padalia B D 1981 Phys. Lett. A84 275

Nagarajan R, Sampathkumaran E V, Vijayaraghavan R and Shenoy G K 1983 J. Less Common Metals 94265

Odoni W and Ott H R 1979 Phys. Lett. A70 480

Ott H R, Odoni W, Fisk Z and Remeika J P 1981 in Ternary superconductors (eds) G K Shenoy, B D Dunlap and F Y Fradin (New York: Elsevier, North Holland), p. 251

Perrin A, Chevrel R, Sergent M and Fischer $\Phi 1980$ J. Solid State Chem. 3343

Perrin C, Sergent M and Prigent J 1973 C.R. Acad. Paris C277 465

Pobell F, Rainer D and Wühl H 1982 in Superconductivity in ternary compounds I, Chapter 7 (eds) $\Phi$ Fischer and M B Maple (New York: Springer Verlag)

Poppe U 1980 Ph.D. Thesis, JÜL-Report 1635, West Germany

Radhakrishnan T S, Janawadkar M P, Devare S H, Devare H G, Pillai T, Janaki R, Umarji A M and Subba Rao G V 1981 in Ternary superconductors (eds) G K Shenoy, B D Dunlap and F Y Fradin (New York: Elsevier North Holland), p. 91

Ramakrishnan T V and Varma C M 1981 Phys. Rev. B24 137

Ramasamy S, Nagarajan T, Umarji A M and Subba Rao G V 1981 Phys. Lett. A81 71

Remeika J P, Espinosa G P, Cooper A S, Barz H, Rowell J M, McWhan D B, Vandenberg J M, Moncton D E, Fisk Z, Woolf L D, Hamaker H C, Maple M B, Shirane G and Thomlinson W 1980 Solid State Commun. 34923

Rogl P 1979 Monatsh Chem. 110235

Rogl P 1980 Monatsh Chem. 111517

Roy U, Das Gupta A and Koch C C 1977 IEEE Trans. on Magnetics MAG-13 836

Ruhl R and Jeitschko W 1979 Mater. Res. Bull. 14513

Rundquist S and Nawapong P C 1966 Acta Chem. Scand. 202250

Rundquist S and Tansuriwongs P 1967 Acta Chem. Scand. 21813

Sakai O, Tachiki M, Koyama T, Matsumoto H and Umezawa H 1981 Phys. Rev. B24 3830

Sampathkumaran E V, Gupta L C and Vijayaraghavan R 1982 Phys. Lett. A88 180

Sankaranarayanan V, Rangarajan G, Srinivasan R, Umarji A M and Subba Rao G V 1982 Cryogenics 22305

Schöllhorn R 1980 Angew. Chem. Int. Ed. Engl. 19983

Schöllhorn R 1983a in Inclusion compounds (eds) J L Atwood, D E D Davies and D D MacNicol (New York: Academic Press)

Schöllhorn R 1983b Comments in Inorg. Chem. 2271

Segre C U and Braun H G 1981 Phys. Lett. A85 372

Segre C U, Braun H F and Yvon K 1981 in Ternary superconductors (eds) G K Shenoy, B D Dunlap and F Y Fradin (New York: Elsevier North Holland), p. 243

Sergent M, Fischer $\Phi$, Decroux M, Perrin C and Chevrel R 1977 J. Solid State Chem. 2287

Shelton R N 1978 J. Less Common Metals 62191

Shelton R N and Johnston D C 1978 in High pressure and low temperature physics (eds) C W Chu and J A Wollam (New York: Plenum) p. 409

Shelton R N, Karcher B A, Powell D R, Jacobson R A and Ku H C 1980a Mater. Res. Bull. 151445 
Shelton R N, Segre C U and Johnston D C 1980 b Solid State Commun. 33843

Shenoy G K, Dunlap B D, Fradin F Y, Sinha S K, Kimbal C W, Potzel W, Probst F and Kalvius G M 1980 Phys. Rev. B21 3886

Shenoy G K, Dunlap B D and Fradin F Y 1981 (eds) Ternary superconductors (New York: Elsevier North Holland)

Shenoy G K, Probst F, Cashion J D, Viccaro P J, Niarchos D, Dunlap B D and Remeika J P 1980 Solid State Commun. 3753

Shenoy G K, Noakes D R and Meisner G P 1982 J. Appl. Phys. 532628

Shoemaker C B and Shoemaker D P 1965 Acta Crystallogr. 18900

Simon A 1981 Angew Chem. Int. Ed. Engl. 201

Sinha S K, Crabtree G W, Hinks D G and Mook H 1982 Phys. Rev. Lett. 48950

Sleight A W, Gillson J L and Bierstedt P L 1975 Solid State Commun. 1727

Stewart G R, Meisner G P and Ku H C 1982 in Superconductivity in d-and f-band metals, (eds) W Buckel and W Weber Kernforschungszentrum Karlsruhe GmbH, Karlsruhe, p. 331

Subba Rao G V and Shenoy G K 1981 in Current trends in magnetism (eds) N S Satyamurthy and L Madhava Rao, Indian Phys. Assoc. Bombay

Suhl H 1978 J. Less Common Metals 62225

Suzuki M, Murakami T and Inamura T 1980 Jpn. J. Appl. Phys. 1972

Suzumura Y and Nagi A D S 1982 Solid State Commun. 41413

Toth L E 1967 J. Less Common Metals 13129

Umarji A M 1980 Ph.D. Thesis, IIT Madras (Unpublished)

Umarji A M, Subba Rao G V, Janawadkar M P and Radhakrishnan T S 1980 J. Phys. Chem. Solids 41421

Umarji A M, Subba Rao G V, Janawadkar M P and Radhakrishnan T S 1981a Solid State Commun. 371

Umarji A M, Subba Rao G V, Sankaranarayanan V, Rangarajan G and Srinivasan R 1981 b in Ternary superconductors (eds) G K Shenoy, B D Dunlap and F Y Fradin (New York: Elsevier North Holland), p. 91

Vandenberg J M 1980 Mater. Res. Bull. 15835

Vandenberg J M and Barz H 1980 Mater. Res. Bull. 151493

Vandenberg J M and Matthias B T 1977 Proc. Nat. Acad. Sci. USA 741336

Woolf L D, Johnston D C, Mackay H B, McCallum R W and Maple M B 1979 J. Low Temp. Phy's. 35651

Yashonath S, Hegde M S, Sarode P R, Rao C N R, Umarji A M and Subba Rao G V 1981 Solid State Commun. 37325

Yvon K 1979 in Current topics in Materials Science (eds) E Kaldis (Amsterdam: North Holland) Vol. 3

Yvon K and Grüttner A 1980 in Supercondictivity in d-and f-band metals (eds) H Suhl and M B Maple (New York: Academic Press), p. 515

Yvon K and Johnston D C 1982 Acta Crystallogr B38 247 